2.4

Analysis of Chemical and Biological Properties

Kelly A. Bérubé, Roy J. Richards, Timothy Jones, Terry Moreno,

Stephen Thomas and Aino Nevalainen

2.4.1

Electron Microscopy-Based Microanalysis of Airborne Particles

\title{
2.4.1.1 Introduction
}

Electron microscopy (EM), namely transmission and scanning, is the most common technique used for particle analysis, at both the morphological and chemical levels; it is assumed that the reader is familiar with the basic principles of electron microscope design and operation and only the practical applications will be considered. In terms of particle identification based on morphology, transmission electron microscopy (TEM) is the more robust system, especially when dealing with airborne particles that are submicron in size. TEM will yield information on the ultrastructure, providing a two-dimensional interpretation of a particle. In contrast, scanning electron microscopy (SEM) is more limited to airborne particles that are microns in size and will produce information about a particle's surface structure or a three-dimensional interpretation.

The added bonus of EM is its capacity to determine the elemental composition of airborne particles, at both the individual and bulk particle levels. Several analytical techniques are available for the elemental characterization of specimens within the electron microscope (e.g. X-ray analysis, Auger electron spectroscopy, and electron energy loss spectroscopy). For all such techniques, a signal is produced by either direct electron bombardment, or by interaction with auxiliary excitation sources (e.g. X-rays) and collected in appropriate detectors (i.e., an energy dispersive spectrometer [EDS]), to yield specific information about the elemental features of a specimen. In the case of particle analysis, elemental characterization is best achieved by means of X-ray detection using a technique more commonly known as electron probe X-ray microanalysis (EPXMA). X-rays within the electron microscope are generated by the interaction of the electron beam with individual atoms in the specimen (e.g. characteristic X-rays). These X-rays carry information about the elemental composition of the specimen in the region that is being irradiated and consequently provide a means of correlating structural information with elemental content. Therefore, in theory, X-ray microanalysis is possible using any electron microscope fitted with a suitable detector system, and this is generally true for qualitative X-ray microanalysis. Quantitative X-ray microanalysis is a

\section{Morawska - Chapter 2-4}


more demanding technique in terms of the additional requirements of electron microscope design, specialist software, and interpretation of the results, and for these reasons the present discussion will be confined to qualitative EPXMA at both the TEM and SEM levels.

TEM is used for EPXMA of thin samples or those capable of allowing the electron beam to be transmitted through the specimen (e.g. carbon-based particles). TEM provides information for X-ray microanalysis at a high spatial resolution because the electrons that pass through the specimen do so with negligible loss of energy and the X-rays generated are uniform throughout the depth of the section (i.e. not absorbed). In contrast, SEM is used for EPXMA of the surface detail in bulk or thick samples (i.e. those capable of stopping the electron beam before it is able to pass through the specimen). It provides information at a lower resolution than TEM because of the wider spread of the electron beam below the surface of the specimen. In other words, as electrons enter the specimen they are scattered laterally and lose energy until they are finally stopped, and hence, the number of characteristic X-rays produced is reduced. It should finally be noted that no single electron microscope technique will provide a total elemental characterization of a specimen and a synergistic approach is generally required, combining several other microanalytical techniques (see Section 2.4.1.2).

\subsubsection{Preparation Methods for Particle Analysis by Transmission Electron Microscopy}

The way in which a specimen is handled in the electron microscope laboratory and the operation during analysis will affect the results obtained. Firstly, it is very easy for samples to become contaminated with elements from the laboratory environment at any stage during specimen preparation and analysis. Therefore, it is recommended that sterile techniques be adopted for all aspects of sample preparation. It should also be noted that unless a bulk chemical analysis is required, the use of wet preparation methods might result in the redistribution of elements within a specimen, which should not pose a problem unless elemental mapping is required (see Section 2.4.1.4). If elemental mapping is required, then dry preparation methods for SEM should be utilized in order to preserve sample elemental integrity (see Section 2.4.1.5).

The chemical analysis of airborne particles by TEM-EPXMA requires that the particles be taken up in solution (wetted) in order to resuspend them onto a specimen support (i.e., a TEM grid covered with a supporting film) (Fig. 2.4-1). For filter-bound particles (Fig. 2.4-2), the simplest way to remove the particles is by ultrasonication of the filter in a solvent. Only a small piece of a collection filter containing particles is needed to obtain a suitable sample size, since EPXMA of particles is best achieved by working with dilute particle suspensions. One means of obtaining a consistently uniform and small sample size from any given filter is to use a hole-punch (e.g. $5 \mathrm{~mm}$ diameter, sterilized before use). If the concentration of the particle suspension needs to be known, then pre- and post-weighting of the filter after removing a filter-disc with the hole-punch may be used to determine the mass of particulate matter on the filter-disc. The filter-disc produced may then 


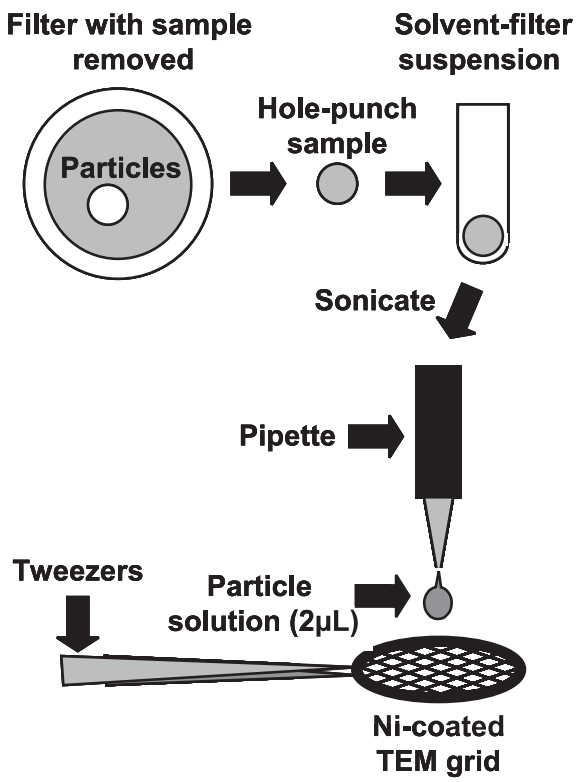

Fig. 2.4-1 Schematic diagram depicting the wet-preparation technique for TEMEPXMA

be placed in an Eppendorf tube (sterile) and wetted with a solvent (e.g. HPLCgrade water). It is important to ensure that the type of solvent used for wetting particles will not degrade the filter material (e.g. Millipore DA filters will degrade following treatment with acetone, and Whatman Cyclopore Track Etch filters will do so following exposure to chloroform (BéruBé et al., 1997). Therefore, it is recommended to test a piece of a blank filter with only the solvent before sacrificing particle suspensions. The wetted particles then require ultrasonication (e.g. 5-15 $\min$ ) to assist their removal from the filter-disc. The time needed for ultrasonication will be dependent upon the durability of the filter (e.g. polycarbonate filters are more resistant to mechanical agitation than nitrocellulose filters (BéruBé, 2003), but it should also be noted that lengthy sonication times would increase individual particle aggregation (BéruBé et al., 1999). A $2 \mu \mathrm{L}$ sample (maximum for a standard TEM grid) may then be aliquoted, using a sterile micropipette, onto a coated grid and then allowed to air dry at room temperature in a sterile covered Petri dish. Particle-free samples consisting of grids that are or are not treated with the solvent should be prepared as controls for traces of contaminating elements that may be found in a variety of support films (e.g. silicon, chlorine or calcium) or in the solvent used. Moreover, elemental contamination will be derived from the grid itself (e.g. copper, nickel, gold, and titanium; see Section 2.4.1.3) and from the electron microscope (e.g. silicon from oil in the vacuum system). Once the grid samples have been air-dried, they may then be analyzed in the TEM using standard EPXMA routines as described below.

Prior to EPXMA, the following information should be considered with regard to sample preparation. Electron microscope grids are made of a number of different 

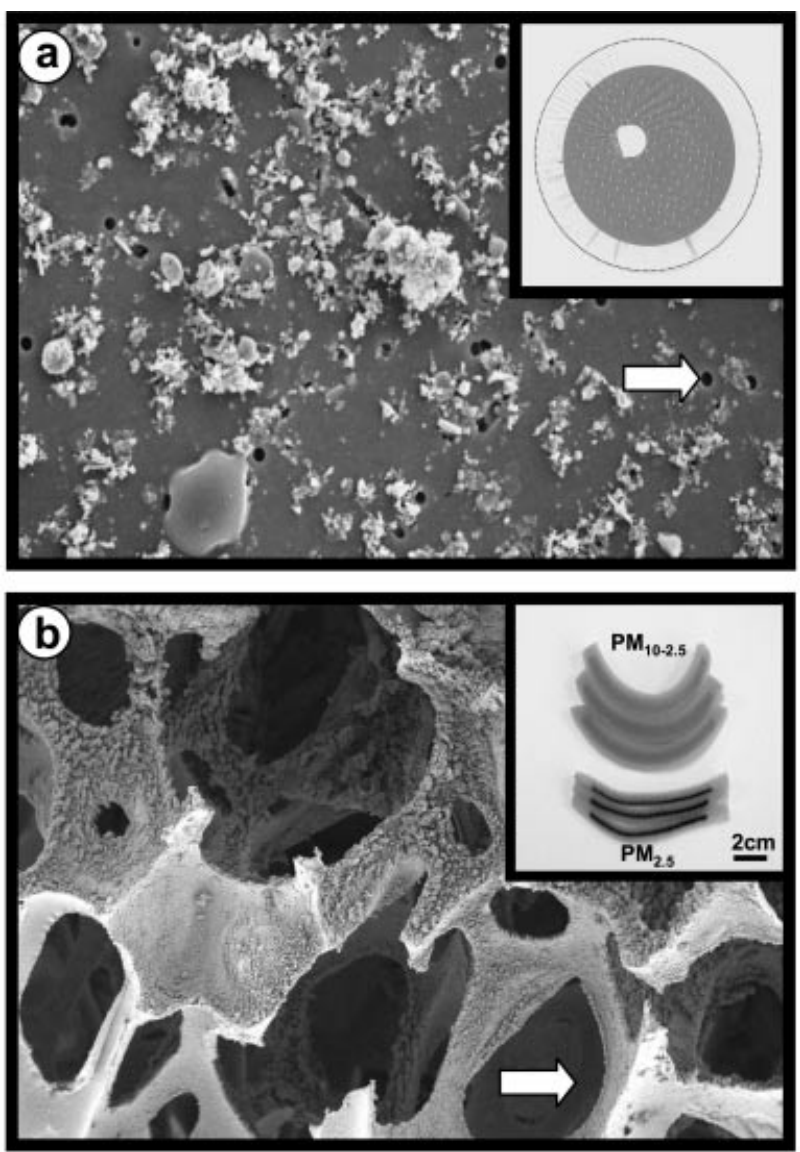

Fig. 2.4-2 Filter-bound particles: a FESEM image of a polycarbonate filter sample of indoor $\mathrm{PM}_{10}$. Arrowhead depicts a pore in the filter. Inset shows the gross filter specimen with a hole-punch $(5 \mathrm{~mm}$ diameter) sample removed. Particles appear as white encrustations on the filter. Dotted line denote perimeter of the $47 \mathrm{~mm}$ diameter filter. b FESEM image of a polyurethane foam filter sample of $\mathrm{PM}_{10}$. Inset shows two gross filter specimens containing coarse (top) and fine (bottom) particles (dark central bands in each of the foams). Particles appear as grey encrustations on the foam (arrowhead). The holes represent the pores in the foam

materials and come in a variety of different mesh sizes. When a specimen is analyzed in the TEM some electrons are scattered and strike the grid bars producing X-rays that may interfere with the detection of elements of interest. For example, if the study in hand requires the detection of nickel and the specimen is already mounted onto a nickel grid, then nickel X-rays caused by scattering will mask those produced from the specimen, so that a grid made from an alternative material, such as copper, should be used. Furthermore, a TEM grid with a wide 
mesh (e.g. 100-mesh) should be selected for use to reduce the mass of material available for interaction with the electron beam and to decrease the likelihood of scattered electrons reaching the grid bars. Finally, since the application of particle analysis requires the TEM grid to be coated with a supporting film, this needs to be thick enough to support the specimen but thin enough to allow the penetration of electrons without loss of resolution. A support film with a thickness between $50 \mathrm{~nm}$ and $90 \mathrm{~nm}$, such as a $0.8 \%$ pioloform film, provides a good substrate for the study of airborne particles.

\subsubsection{Qualitative Electron Probe X-Ray Microanalysis in the Transmission Electron Microscope}

The conditions for using the electron microscope need to be pre-determined before $\mathrm{X}$-ray microanalyses are made on a routine basis. These conditions will depend on the nature of the specimen, the experimental design, and the type of electron microscope available. The general approach is to select conditions (e.g. magnification, voltage, apertures, probe current, and duration of analysis) that maximize the number of counts in the characteristic X-ray peaks while minimizing beam damage, and resultant loss of elemental mass, to the specimen. Once the optimal conditions have been determined, analysis of the specimen may proceed as follows:

1. Insert a grid bearing the sample into the TEM and obtain an image.

2. Select area of interest.

3. Adjust probe size.

4. Perform analysis using the pre-determined conditions.

5. Collect and store the spectrum.

6. Photograph the specimen and the area analyzed.

For qualitative EPXMA, the EDS is a fast detector system within an electron microscope and the emitted X-rays collected are displayed as a spectrum. A spectrum is the frequency plot of the number of characteristic X-ray peaks produced by the interaction of the incident electrons from the beam with orbital electrons in atoms, versus X-ray energy. All the elements present in the area that is being irradiated contribute to the production of an X-ray spectrum and are detected simultaneously in a single analysis (Fig. 2.4-3; BéruBé and Richards, 2001). The resultant spectra may be quite complex and a rigorous and systematic approach should be adopted for the identification of peaks and spectral interpretation. The following rules provide good practical advice on how best to undertake qualitative EPXMA in the electron microscope (e.g., see also Morgan, 1984; Morgan et al., 1999; Warley, 1997):

1. Only peaks that are statistically significant should be used for identification purposes (i.e. where the counts in the peak $(P)$ are more than three times the count in the background (B) under the peak).

2. If a spectrum is generated with only a few high peaks, check to ensure that these are not due to pulse-pile up (e.g. sum peaks) or escape peaks that appear below the parent peak. 

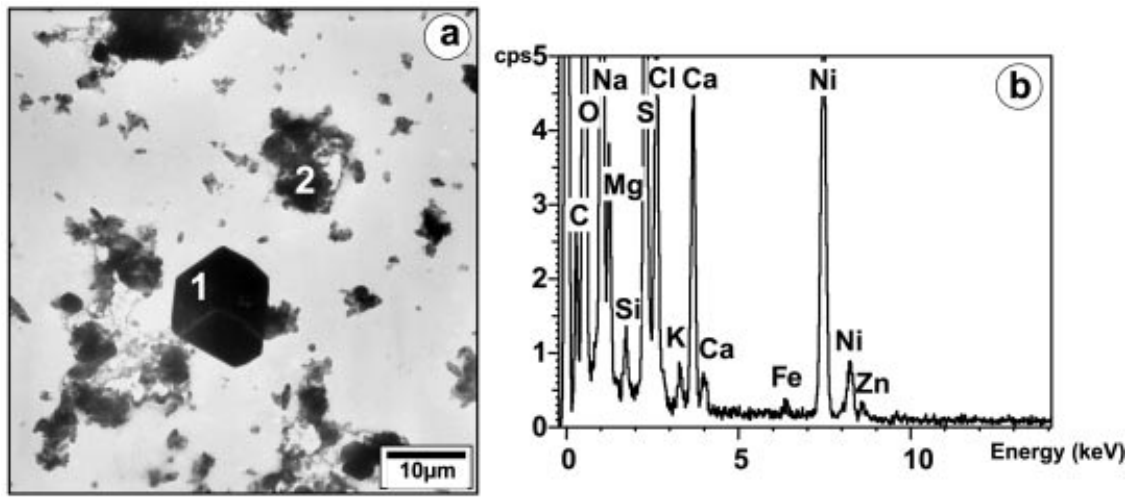

Fig. 2.4-3 TEM-EPXMA of indoor $\mathrm{PM}_{10}$ : a typical electron micrograph of particles ( 1 =salt crystal; 2 =soot particles) suspended on a pioloform-coated TEM grid; $\mathbf{b}$ typical X-ray spectrum generated by irradiation of particles in a suspended on a pioloform-coated TEM grid. Nickel peaks are from the TEM grid

3. When assigning a peak for characteristic X-rays, look for accompanying lines in that family (e.g. for elements with atomic number greater than 17 [chlorine] both $\mathrm{K} \alpha$ and $\mathrm{K} \beta$ peaks should be present).

4. If an electron beam is sufficient to generate a given X-ray line, it should generate all other lines of lower energy (e.g., if the $\mathrm{K}$ lines of an element have been positively identified, then look for the $\mathrm{L}$ and $\mathrm{M}$ lines in the spectrum).

5. Ensure that peaks originated from the specimen by eliminating the possibility that they were generated by extraneous sources (e.g., the TEM grid or microscope parts).

6. Remember that the overlap of adjacent peaks is frequently encountered and may result in peak misidentification (i.e. peaks separated by $\sim 50 \mathrm{eV}$ cannot be successfully deconvoluted and a major peak may contribute to a minor peak even when they occur $200 \mathrm{eV}$ apart).

\subsubsection{X-Ray Elemental Mapping Using Transmission Electron Microscopy}

For the qualitative assessment of the gross distribution of an element in a specimen, X-ray elemental mapping is an additional technique that may be used, provided that the TEM is fitted with a scanning attachment. The key feature of 'digital' mapping is the manner in which the electron probe is scanned across the specimen. Instead of the probe being moved continuously across the specimen, as in SEM, the probe dwells for a given period of time (i.e., the dwell time) at a single point on the specimen and then is rapidly moved on to the next point. The overall result is an elemental image map that is built up as a mathematical matrix of points (e.g. pixels). The operator determines the dwell time and increasing it 


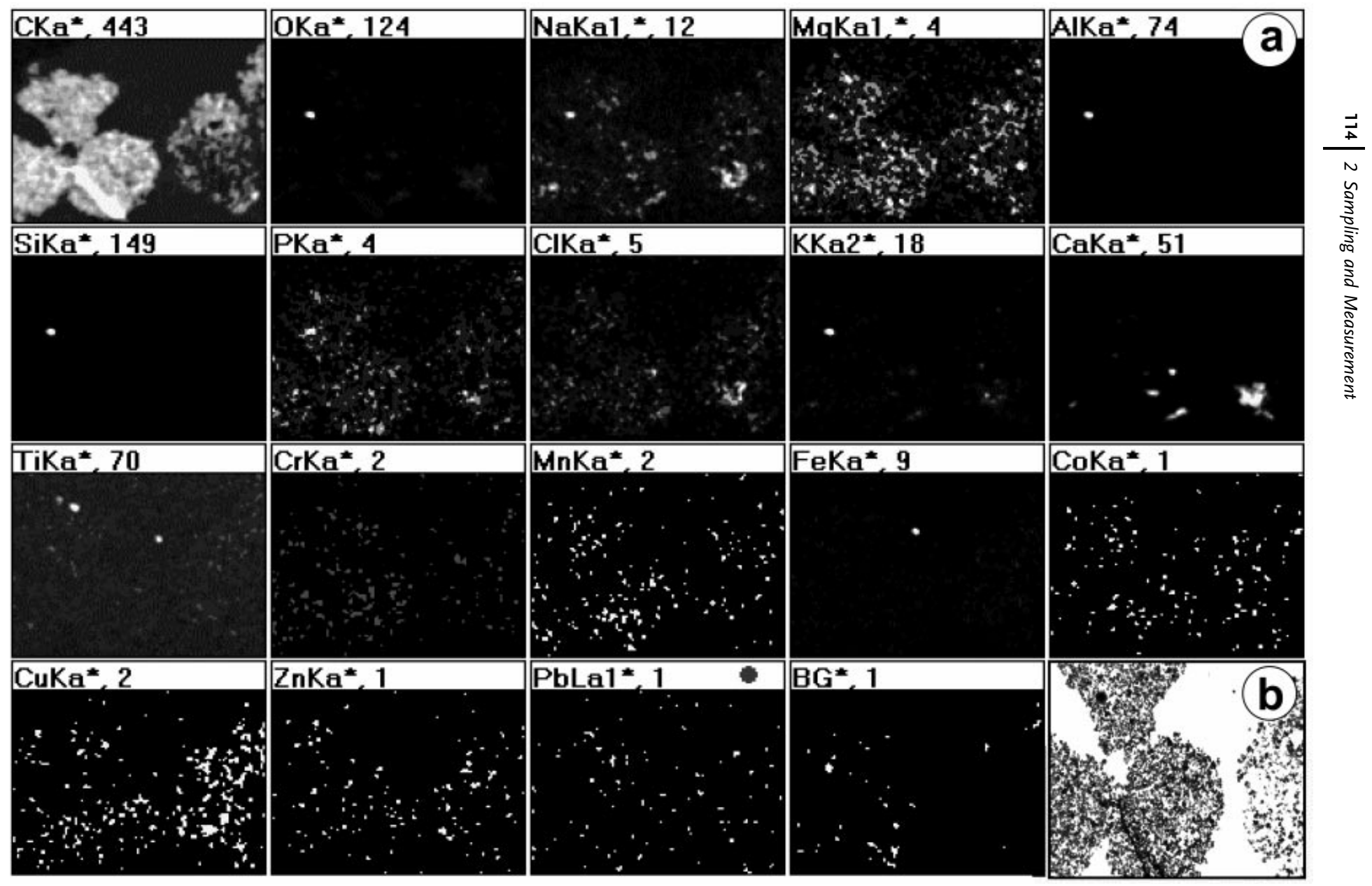

Fig. 2.4-4 Demonstration of the multi-element capability of TEM-EPXMA: a digital X-ray map revealing the chemical heterogeneity of PM 10 soot particles; b corresponding electron image for a 
per pixel can increase the reliability of the data. In addition, data for a number of elements can be collected simultaneously since X-ray collection windows are preset for all the elements of interest and the only limitation is the size of the storage memory of the computer. Thus, the multi-element capability of EPXMA can be realized, yielding a wealth of information about the chemical heterogeneity of the specimen (Fig. 2.4-4a; BéruBé et al., 1997). Finally, an electron image of the area of interest can also be collected at the same time, so that the distribution of the elements can be directly related to the electron image (Fig. 2.4-4b).

Digital elemental maps can be collected either as qualitative or as quantitative maps; only qualitative methods will be described here, given the specialist software required for the latter technique. To collect a qualitative X-ray map, the same operating conditions are established and analysis routines performed as outlined above (see Section 2.4.1.3) for standard qualitative TEM-EPXMA. Once a spectrum is obtained from this analysis, the operator selects any element(s) that appear(s) in that spectrum (i.e. sets a window or windows over the energy regions occupied by the characteristic X-ray peaks, including elements of the grid/holder). For control purposes, a window is also set to produce a map of the background or continuum radiation, since this can vary according to specimen topography, which may interfere with the observed distribution of elements. The data from the background map should be subtracted from each element map generated to correct for such artefacts. A dwell time is then set, which, when increased, augments the X-ray counts collected (as does intensifying the beam current). EPXMA is then repeated but in the scan mode (not static probe mode), and only data for the elements of interest selected (windowed) from the spectrum are collected. During collection of the map, the number of counts in each of these windows at every pixel is stored to disk and is thus available for further processing (e.g. background map subtraction). Collection of data as total peak counts results in a purely qualitative map that is used to demonstrate the distribution of elements. The results from such an analysis are presented in a visual format, which is often easier to assimilate than tables of numerical data. Meaningful elemental maps can be obtained by ensuring the following conditions (see also Morgan, 1984; Morgan et al., 1999; Warley, 1997):

1. 20000 counts per micrograph.

2. $\mathrm{P} / \mathrm{B}$ ratio of $3: 1$.

3. Set a continuum map for control purposes.

\subsubsection{Preparation Methods for Particle Analysis by Scanning Electron Microscopy}

For the chemical analysis of airborne particles by SEM-EPXMA, both wet and dry sample preparation methods may be used. It should be reiterated that unless a bulk chemical analysis is required, the use of wet preparation methods might result in the loss of soluble components and/or redistribution of elements. If elemental mapping is required, then dry preparation methods should be utilized.

The wet preparation of filter-bound particle samples utilizes the same procedures as outlined for TEM (see Section 2.4.1.2), the only difference being the type 
(a)

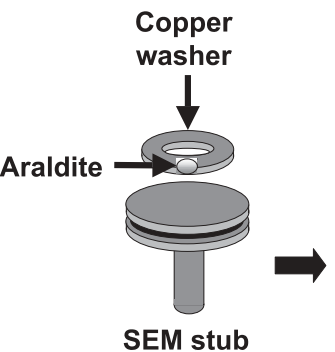

(b)

$5 \mathrm{~mm}$ filter

hole punch

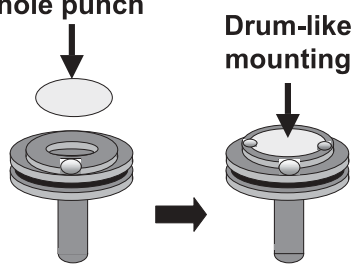

(C)

(d)

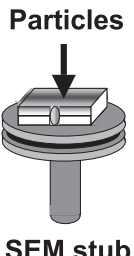

Fig. 2.4-5 Schematic diagram for FESEM polycarbonate filter (a-c) and polyurethane foam sample preparation (d): a fixing washer to SEM stub; b Araldite filter sample onto washer; c completed sample 'drum'; d foam substrate is fixed with Araldite directly to the SEM stub

of specimen support system required. The ideal specimen support used for SEMEPXMA is an aluminum pin stub, upon which the particle/solvent preparation may be aliquoted ( $20 \mu \mathrm{L}$ is ideal for a $12.5 \mathrm{~mm}$ stub) using a sterile micropipette, and then allowed to air-dry at room temperature in a covered SEM storage box. Evaporation of the solvent leaves the particles secured to the stub surface by electrostatic forces. Sterile techniques should again be adopted and the stubs should first be washed in $70 \%$ ethanol and allowed to air-dry before use. Control samples should also be prepared (see Section 2.4.1.2) consisting of stubs, some treated and some not treated with the solvent, in order to identify any elemental contamination (e.g. from the stub, detritus, or EM hardware). When the stub samples have been air-dried, they may then be analyzed in the SEM according to the EPXMA guidelines described below (see Section 2.4.1.6).

The dry preparation of filter-bound particle samples requires a unique specimen mounting technique developed by Jones et al. $(2001,2002)$ and BéruBé et al. (2003). This technique is ideal for thin filter substrates such as polycarbonate filters, which cannot be traditionally 'flat-mounted' onto the SEM pin stubs since the epoxy resin (Araldite) used for mounting is drawn by capillary action through the filter holes, obliterating the filter surface. In order to resolve the problem of capillary diffusion of the mounting medium, small pieces of filter (e.g. $5 \mathrm{~mm}$ hole punches) need to be mounted on a structure that isolates the filter from contamination by adhesive, yet also ensures an electrical pathway to prevent specimen 'charging'. The first stage involves fixing a $4 \mathrm{~mm}$ (internal diameter) copper washer (washed in 70\% ethanol before use) onto a $12.5 \mathrm{~mm}$ (sterile) SEM pin stub with an epoxy resin such as Araldite (Fig. 2.4-5a). A small dab of Araldite is placed on the side of the washer to ensure a 'bridge' is made between the top surface of the washer and the top of the pin stub in order to avoid excessive charging in the sample. A hole punch can be used to cut a $5 \mathrm{~mm}$ diameter circle from a filter that can then be epoxy-resined over the hole in the washer (Fig. 2.4-5 b), creating a 'drum-like' mounting (Fig. 2.4-5 c). 
When using substrates thicker than a polycarbonate filter, such as polyurethane foams (PUF; thickness $\sim 1 \mathrm{~cm}$, Fig. 2.4-5d), the Araldite does not produce the mounting problems described above. Therefore, the more traditional flat-mounting techniques can be used, whereby a thin layer of adhesive (Araldite) is distributed uniformly over the stub surface for substrate adherence. In addition, a small amount of Araldite is also placed on the side of the foam, linking the SEM stub surface with the top of the foam sample (where the particles are trapped), in order to avoid charging.

For both types of dry preparations, control samples should also be prepared consisting of stubs that contain a blank piece of the collection filter being used as well as a stub with a dab of adhesive only, in order to identify any elemental contamination. Most particle filters contain a plethora of different elements (e.g. polycarbonate filters contain significant traces of zinc) and some adhesives are known to act as a source of chlorine, sodium, and sulfur (see below).

The following information should be taken into account with regard to sample preparation for SEM. When samples are analyzed in the SEM, the electron beam does not penetrate the specimen and so the composition of the specimen stub is not that important. Nevertheless, scattered electrons can still excite X-rays from the stub, and thus it is best to use a stub material that will make little or no contribution to the X-ray spectrum. This should not pose a problem since SEM stubs are made from a variety of different materials aside from aluminum (e.g. carbon (graphite) or beryllium). It is also important to ensure that the sample is attached securely to the stub surface so that charging does not occur. In wet preparation techniques, the particles will be held in place by electrostatic forces following evaporation of the solvent by air-drying. In the case of dry sample preparations, although the use of an epoxy resin was described here, there are a variety of other adhesives available (e.g. sticky tapes, silver dag). The choice of adhesive depends upon the mode of SEM being employed. For example, if field emission SEM is intended, it is recommended that adhesives such as carbon tabs be avoided, since they create volatile organic compounds in the EM vacuum system which accumulate on electron filaments and reduce image quality. Moreover, if an epoxy resin is used as an adhesive for FESEM analysis, then a slow setting (e.g. 24 h) Araldite should be used since fast curing Araldite also produces volatiles. Finally, when manipulating a specimen for attachment to the stub it is important that other surfaces do not come into contact with the adhesive material and pick up contaminating elements. For example, sticky tapes are known to act as a source of chlorine and carbon tabs may contain sodium and sulfur (Warley, 1997).

Once the particle sample (wet or dry preparations) is securely mounted onto the stub, sample coating may be necessary depending upon the application (i.e. imaging or elemental analysis). In order to study samples in the SEM they must be electrically conductive to minimize charging, and this is achieved by coating them with a thin (up to $50 \mathrm{~nm}$ ) layer of carbon or a metal. Carbon is the most common coating material, followed by gold/palladium, especially when performing FESEM, to obtain better quality images (Burnstock and Jones, 2000). If the particle sample has been coated, it must be remembered that the coating material will generate X-ray peaks 
that may coincide with elements found in the specimen. Moreover, if coating is not required, for example, when analyzing carbonaceous particles, it should be noted that uncoated aluminum stubs would produce a large aluminum K X-ray peak that may interfere with the K peak from any magnesium in the sample (Warley, 1997). Once the samples have been secured to the stub, the adhesive has set, and a coating (if necessary) has been applied, they may then be analyzed in the SEM according to the EPXMA guidelines described below (see Section 2.4.1.6).

\subsubsection{Qualitative Electron Probe X-Ray Microanalysis in the Scanning Electron Microscope}

In general, the same guidelines as outlined for qualitative TEM-EPXMA (see Section 2.4.1.3), i.e. selecting EM operating conditions, analysis steps, and rules for assessing data, should also be followed when performing EPXMA on particle samples in the SEM. The major difference is the choice of accelerating voltage; thus, voltages between 10 and $20 \mathrm{kV}$ are generally used for SEM-EPXMA. The data output for qualitative SEM-EPXMA is the same as that for TEM, where all of the elements present in the area that is being irradiated contribute to the production of an X-ray spectrum and are detected simultaneously in a single analysis (Fig. 2.4-6; Moreno et al., 2003). It is also possible to relate chemical content to particle morphology, since an electron image of the area of interest can also be collected at the same time (Fig. 2.4-6).

\subsubsection{X-Ray Elemental Mapping Using Scanning Electron Microscopy}

The technique of digital X-ray elemental mapping previously described for TEM (see Section 2.4.1.4) may also be realized in SEM. The key difference will be in the spatial resolution of elements detected, digital elemental mapping by TEM being the more robust technique. In other words, elemental mapping by SEM is less reliable for demonstrating the distribution of elements present at low concentrations. In a manner similar to X-ray mapping by TEM, a multi-element capability can be realized, and the maps generated are correlated with the image of the area of interest, thus providing a visual assessment of the elemental distributions within a particulate matter sample (Fig. 2.4-7; Moreno et al., 2003). Once again, the same guiding principles summarized above (see Section 2.4.1.4) for digital mapping by TEM should be considered.

\subsubsection{Advantages and Disadvantages of Electron Microscopy-Based Microanalysis}

EPXMA is not suitable for the detection of trace amounts of elements evenly dispersed throughout a matrix. The technique is, however, extremely efficient in detecting the presence of elements that are highly localized. All of the elements present in the area that is being irradiated contribute to the production of an X-ray spectrum and are detected simultaneously in a single analysis. This has the ad- 

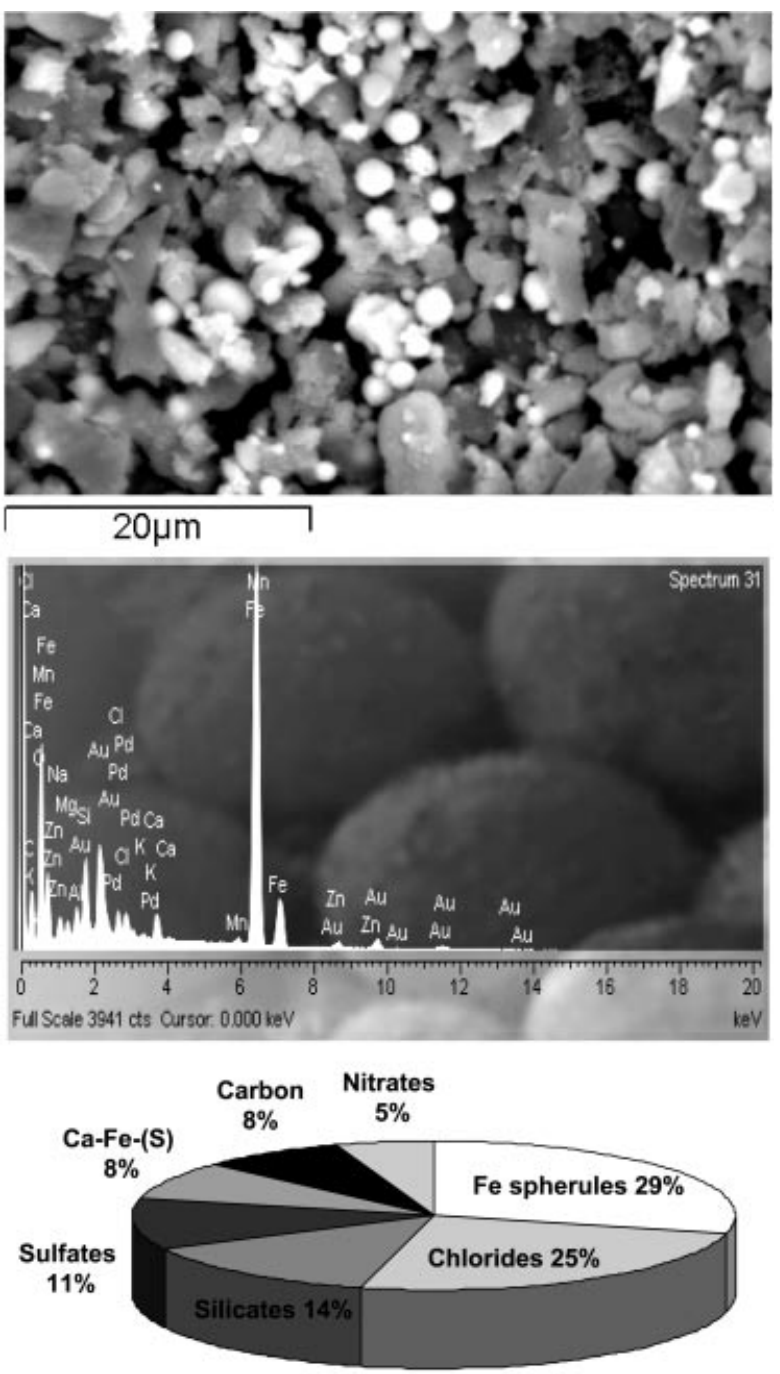

Fig. 2.4-6 SEM-EPXMA of $\mathrm{PM}_{10}$ : a typical electron micrograph of coarse particles collected on a PUF; $\mathbf{b}$ typical $\mathbf{X}$-ray spectrum generated by irradiation of particles in (a) suspended on a PUF substrate, coated with palladium/gold and mounted on an aluminum SEM stub; c example of data output for SEM-EPXMA: pie diagram generated for a $\mathrm{PM}_{10}$ 2.5 sample after a minimum of 500 SEM-EPXMA analyses

vantage that it eliminates the need for sequential screening for different elements, and it can reveal the presence of unsuspected elements. However, it must be realized that the technique detects nuclides of elements only and no information about the chemical state (bound or free, isotopic or redox states) of the element can be inferred. 


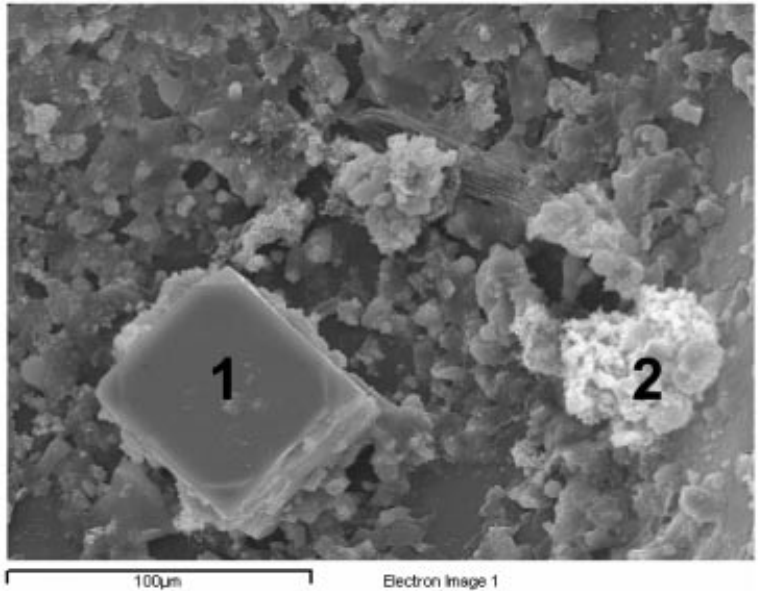

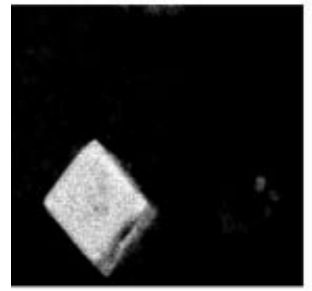

Criorine KaI

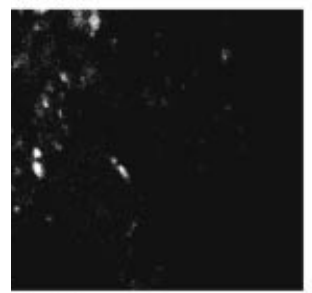

Siliconka1

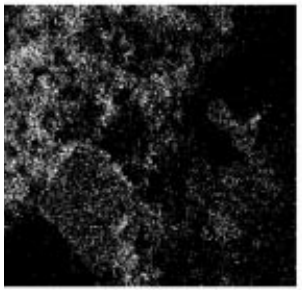

Potassium Ka1

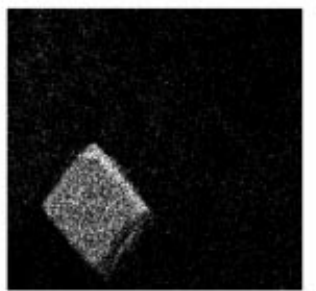

Sodum Kat 2

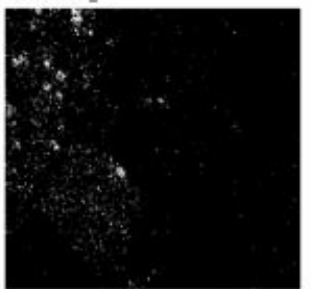

A.juninun Ka1

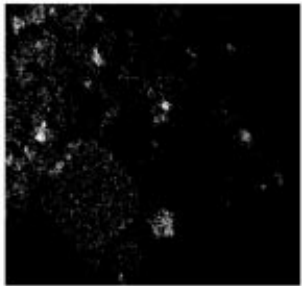

SulfuKal

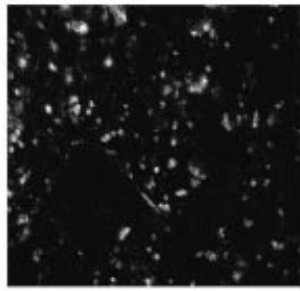

ronkal

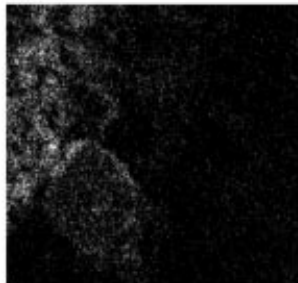

Magnesium Ka1_2

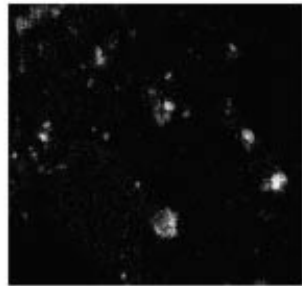

Cacien Kal

Fig. 2.4-7 Example of the multi-element capability of SEM-EPXMA: a typical electron micrograph of particles $(1=$ salt crystal; $2=$ soot particles) suspended on a PUF coated with palladium/gold and mounted onto an aluminum SEM stub; $\mathbf{b}$ digital $\mathbf{X}$-ray map revealing the chemical heterogeneity of the $\mathrm{PM}_{10}$ particles in a 
The only major drawback of this technique, as it is applied to particle analysis, is self-evident in that wetting the particles may produce soluble components that could dissociate from the parent particle(s). This potential problem may be addressed by analyzing apparent particle-free areas of the grid support film to see if elements other than those found in control samples may be detected. If so, one way to overcome this problem is to prepare both soluble and insoluble particle fractions for comparative analysis. Despite this solubility problem, the benefits of EPXMA make it an ideal technique for the elemental analysis of particles in that it requires a small sample size and is one of the few techniques that permit chemical data to be directly related to morphological data.

\subsubsection{Summary}

The spatial resolution of EPXMA is unsurpassed by any other analytical technique that combines simultaneous compositional and morphological observation. For the purpose of determining the chemical species of a given particulate matter sample, both TEM and SEM-EPXMA will provide the user with information on the inorganic chemical composition and the location of the element(s) present at both an individual particle and bulk particle level.

\subsection{2}

\section{Chemical Analysis of Inorganic Particles}

\subsubsection{Methods for the Analysis of Inorganic Particles}

Methods for the chemical analysis of inorganic particles in indoor air are the same as those methods employed (e.g. Claes et al., 1998) for analyses of particles in outdoor ambient air. While these methods have been used extensively to characterize ambient air, indoor air does not receive as much attention with regard to these types of analyses.

The methods are generally indirect, relying upon sample collection prior to chemical analysis. Filtration is the technique that is often employed to collect the aerosols for further analysis. A major problem encountered in the filter collection technique is the sampling of sufficient mass of particles for analysis. Because of the very low concentrations typical of many inorganic particles in the indoor environment, the quantities of particles sampled and deposited onto the filters for analysis are very small.

In general, the methods for the analysis of chemical composition of inorganic particles can be divided into two categories:

1. Methods that require sample collection followed by a chemical preparation stage.

2. Methods that involve direct introduction of the filters into the instruments for chemical analysis.

Those methods of category 1 usually involve a form of chemical preparation designed to solubilize the particles, followed by the introduction of the resulting so- 
lution into an instrument for analysis. The chemical preparation stage must therefore dissolve the particles adequately for instrumental detection while also maintaining high levels of purity so as not to contaminate the sample. The instruments commonly employed for these types of analyses either involve chromatographic or colorimetric techniques for the analysis of water-soluble ions. Furthermore, spectrometric techniques such as Flame Atomic Absorption Spectrometry (FAAS), Graphite Furnace Atomic Absorption Spectrometry (GFAAS), Inductively Coupled Plasma - Atomic Emission Spectrometry (ICP/AES), and Inductively Coupled Plasma - Mass Spectrometry (ICP/MS) are used for the analysis of elements.

The methods that involve direct introduction of the filters into the instruments for chemical analysis are also predominantly concerned with the analysis of elements, and include techniques such as Instrumental Neutron Activation Analysis (INAA), X-ray Fluorescence (XRF), and Particle-Induced X-ray Emission (PIXE). These techniques may be further categorized as destructive (INAA) or non-destructive (XRF and PIXE); the latter leave the sample intact after analysis.

The selection of instrument for the analysis thus requires a choice that allows for high sensitivity or low detection limits, accuracy, high selectivity, and an absence of interferences. Tabs. 2.4-1 and 2.4-2 contain some of the ions and inorganic elements that may be found in indoor air and include typical detection limits for the instrumental techniques described in this section.

\subsubsection{Analysis of Water-Soluble lons}

Analyses of water-soluble ions can be divided into two main classes: ion chromatographic (IC) and colorimetric analysis. In both techniques, the water-soluble ions in the air sample are usually collected onto Teflon filters, which are then immediately stored at less than $4{ }^{\circ} \mathrm{C}$ to avoid loss due to volatilization (e.g. ammonium nitrate). The ions are then dissolved in deionized-distilled water (DDW) as the first step of the sample preparation stage.

In IC, the sample solution passes through an ion-exchange column that partitions the ions between a stationary phase and a mobile phase. Components of a mixture are carried through the stationary phase by the flow of the mobile one. Ionic components of the sample are separated by selective exchange with counterions of the stationary phase. The use of ion-exchange resins as the stationary phase brings about a classification based largely on geometry and size. The ions are identified by their elution/retention times and are quantified by the conductivity peak area or peak height, usually by an electro-conductivity detector. IC can be used for both anions $\left(\mathrm{Br}^{-}, \mathrm{Cl}^{-}, \mathrm{F}^{-}, \mathrm{NO}_{2}^{-}, \mathrm{NO}_{3}^{-}, \mathrm{PO}_{4}^{3-}, \mathrm{SO}_{3}^{-}, \mathrm{SO}_{4}^{2-}\right)$ and cations $\left(\mathrm{K}^{+}\right.$, $\mathrm{Na}^{+}, \mathrm{NH}_{4}^{+}$) with separate columns.

In colorimetric techniques, each sample is mixed with a reagent such as methylthymol blue and subjected to an appropriate reaction period. The ion being measured usually reacts to form a colored liquid. Beer's Law relates the liquid $\mathrm{UV} /$ vis absorbance to the amount of the ion in the sample. The analysis stage in colorimetry involves the passage of radiation through an unknown sample solu- 
Tab. 2.4-1 Instrumental detection limits for water-soluble ions on particles

\begin{tabular}{|c|c|c|}
\hline \multicolumn{3}{|c|}{ Species minimum detection limit $\left.\left(\mathrm{ng} \mathrm{m}^{-3}\right)^{a}\right)$} \\
\hline & $\left(c^{b)}\right.$ & $A C^{b)}$ \\
\hline $\mathrm{Cl}^{-}$ & 50 & NA \\
\hline $\mathrm{NO}_{3}^{-}$ & 50 & NA \\
\hline $\mathrm{SO}_{4}^{2-}$ & 50 & NA \\
\hline $\mathrm{NH}_{4}^{+}$ & NA & 50 \\
\hline \multicolumn{3}{|c|}{ IC = Ion Chromatography. } \\
\hline \multicolumn{3}{|c|}{$\mathrm{AC}=$ Automated Colorimetry } \\
\hline \multicolumn{3}{|r|}{ of the blank for a filter of $1 \mathrm{mg}$} \\
\hline \multicolumn{3}{|r|}{$\begin{array}{l}\text { 1artz-fiber filter in } 15 \mathrm{~mL} \text { of deion } \\
\text { 24-h samples. }\end{array}$} \\
\hline
\end{tabular}

tion and measurement of the absorbance of the solution, which is then compared with a set of standards. Automated colorimetric analysis (AC) applies different colorimetric analyses to small sample volumes with automatic sample throughput. The heart of the automated colorimetric system is a peristaltic pump, which introduces air bubbles into the sample stream at known intervals. These bubbles separate samples in the continuous stream. After the reaction is complete, the sample solution in the colorimetric technique is usually introduced into a colorimeter, where a photomultiplier tube is used to measure the absorbance through an interference filter specific to the ionic species being measured. Since IC provides multi-species analysis for the anions, colorimetric techniques are most commonly used to measure $\mathrm{NH}_{4}^{+}$.

Jones et al. (2000) employed IC for the analysis of the anions $\mathrm{Cl}^{-}, \mathrm{SO}_{4}^{2-}$, and $\mathrm{NO}_{3}^{-}$ in size-fractionated particles, and $\mathrm{AC}$ for the analysis of $\mathrm{NH}_{4}^{+}$in indoor environments. The particles were collected, using modified Andersen cascade impactors sampling at $28.3 \mathrm{~L} \mathrm{~min}^{-1}$, on QMA filters for $24 \mathrm{~h}$ sampling periods, and material from segments of these filters was extracted into $15 \mathrm{~mL}$ DDW. The elution of the cations was achieved by using sulfuric acid as the eluent and potassium hydroxide as the suppressant for the IC analysis. For the AC analysis the flow injection procedure described by Genfa and Dasgupta (1989) was employed. The size-fractionated chemical composition (dia. $<1.1 \mu \mathrm{m}, 1.1<$ dia. $<2.1 \mu \mathrm{m}, 2.1<$ dia. $<10 \mu \mathrm{m}$ ) reported by the authors (Jones et al., 1999) for one roadside house is presented in Tab. 2.4-3.

\subsubsection{Flame and Graphite Furnace Atomic Absorption Spectrometry}

In FAAS (Flame Atomic Absorption Spectrometry) the sample is first extracted with a solvent to dissolve the solid material, which usually includes a portion or the entire filter. Typical solvents include strong acids or mixtures of acids such as $\mathrm{HNO}_{3}, \mathrm{HF}, \mathrm{HCl}$, and $\mathrm{HClO}_{4}$. The solution containing the dissolved solids is then extracted into DDW, a dilute acid (typically $5 \% \mathrm{v} / \mathrm{v} \mathrm{HNO}_{3}$ ), or an organic solvent. 
Tab. 2.4-2 Instrumental detection limits for elements on particles

\begin{tabular}{|c|c|c|c|c|c|c|}
\hline \multicolumn{7}{|c|}{ Detection limit $\left(\mathrm{ng} \mathrm{m}^{-3}\right)^{a)}$} \\
\hline Species & $G F A A S^{b)}$ & $I C P / A E S^{c)}$ & $I C P / M S^{d)}$ & $I N A A^{f)}$ & $X R F^{g)}$ & $P I X E^{h)}$ \\
\hline $\mathrm{Na}$ & & & & 1.5 & $7^{\text {g) }}$ & 3 \\
\hline $\mathrm{Mg}$ & 52 & 170 & & 5.7 & $2^{g)}$ & 0.4 \\
\hline $\mathrm{Al}$ & & & & 0.68 & $1.5^{\mathrm{g})}$ & 0.2 \\
\hline $\mathrm{Si}$ & & & & NA & & 0.11 \\
\hline S & & & & 457 & $1.5^{\mathrm{g})}$ & 0.1 \\
\hline $\mathrm{Cl}$ & 43 & & & 5.6 & $0.4^{\mathrm{g})}$ & 0.08 \\
\hline $\mathrm{K}$ & 25 & & & 3.5 & $0.1^{\mathrm{g})}$ & 0.06 \\
\hline $\mathrm{Ca}$ & & 1789 & 11 & 2.8 & $0.06^{\mathrm{g})}$ & 0.04 \\
\hline $\mathrm{Ti}$ & 11 & 1.04 & 2.3 & 2.9 & $1.9^{\mathrm{e})}$ & 0.02 \\
\hline V & 0.09 & & 0.75 & 0.018 & $1.5^{\mathrm{e})}$ & 0.009 \\
\hline $\mathrm{Cr}$ & 4.5 & & 2.3 & 1.5 & $1.2^{\mathrm{e})}$ & 0.006 \\
\hline $\mathrm{Mn}$ & 0.70 & 1.78 & 0.75 & 0.011 & $0.92^{\mathrm{e})}$ & 0.005 \\
\hline $\mathrm{Fe}$ & 17 & 62.74 & 40 & 22 & $0.79^{\mathrm{e})}$ & 0.004 \\
\hline $\mathrm{Ni}$ & 1.7 & 0.37 & 6 & & $0.59^{\mathrm{e})}$ & 0.0035 \\
\hline $\mathrm{Cu}$ & 5.9 & 0.31 & 6.8 & 0.9 & $0.52^{\mathrm{e})}$ & 0.0035 \\
\hline $\mathrm{Zn}$ & 35 & & 20 & 1.4 & $0.47^{\mathrm{e})}$ & 0.0035 \\
\hline $\mathrm{Br}$ & 3.7 & & & & & 0.008 \\
\hline $\mathrm{Pb}$ & 0.93 & 1.41 & 1.5 & & $0.77^{\mathrm{e})}$ & 0.015 \\
\hline
\end{tabular}

a Minimum detection limit is three times the standard deviation of the blank and calculated according to the sampling regime of the research cited.

b Based on calculated concentrations from the GFAAS analysis of $25.92 \mathrm{~m}^{3}$ aerosols collected onto cellulose filters $\left(0.45 \mu \mathrm{m}\right.$ pore size, $47 \mathrm{~cm}$ dia.) and extracted into $\mathrm{HNO}_{3}$ and $\mathrm{HF}$ as reported by Rizzio et al. (2001).

c Blank concentration levels based on the extraction of $3264 \mathrm{~m}^{3}$ of aerosols collected onto segments $(5.6 \times 5.6 \mathrm{in})$ of Whatman glass fiber filters with a mixture of nitric and perchloric acids $(5: 2)$, as reported by Fernández Espinosa et al. (2001).

d Based on calculated concentrations from the ICP-MS analysis of $0.4 \mathrm{~m}^{3}$ of submicrometer aerosols collected onto HV Millipore membrane filters $(0.45 \mu \mathrm{m}$ pore size, $13 \mathrm{~mm}$ diameter $)$ and extracted into $5 \mathrm{~mL} \mathrm{HNO}_{3}(10 \% \mathrm{v} / \mathrm{v})$, as reported by Thomas and Morawska (2002).

e Based on calculated concentrations from XRF analysis of $1.699 \mathrm{~m}^{3}$ of aerosols collected onto polycarbonate filters $\left(0.8 \mathrm{~mm}\right.$ pore size), extracted into $990 \mu \mathrm{L}$ of $\mathrm{HNO}_{3}$, and pipetted $(30 \mu \mathrm{L})$ onto a polished quartz glass carrier for analysis, as reported by Schmeling (2001).

f Concentration is based on INAA of $\sim 20 \mathrm{~m}^{3}$ of fine particulate aerosols collected onto a half-segment of a $47 \mathrm{~mm}$ nucleopore polycarbonate membrane filter, as reported by Salma and ZemplenPapp (1999).

g Concentration is based on the XRF analysis of aerosols collected directly onto polycarbonate reflectors inserted into a five-stage Batelle-type impactor. The sampling time was $2 \mathrm{~h}$ and the flow rate $1 \mathrm{~L} \mathrm{~min}^{-1}$, as reported by Streli et al. (1999).

h As estimated from the graph of detection limits in $\mathrm{ng} \mathrm{m}^{-3}$ per impactor stage based on the

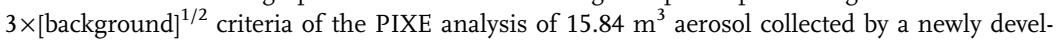
oped small deposit area low-pressure impactor onto polycarbonate film, as reported by Maenhaut et al. (1996). 
The sample preparation stage for GFAAS (Graphite Furnace Atomic Absorption Spectrometry) is usually the same as that used for FAAS. An advantage of GFAAS, however, is the relatively small sample size required (of the order of $20 \mu \mathrm{L}$ ) for analysis. This results in improved sensitivity for the majority of elements (see Tab. 2.4-2). In addition, any losses or contamination problems inherent in the sample pre-treatment stage are eliminated by the introduction of the filters into the graphite tube, allowing direct analysis by GFAAS (Matousek and Brodie, 1973). The applicability of direct sampling without the need for the filters has also been demonstrated by a number of researchers who sampled directly onto the graphite tubes (Woodriff and Lech, 1972; Liang et al., 1990).

In AAS, a few millilitres of the sample solution extract are introduced into a flame for FAAS (or a furnace for GFAAS), where the elements are vaporized. Most elements will absorb light at certain wavelengths in the visible spectrum, and a light beam of specific wavelength, usually from a hollow-cathode or electrodeless discharge lamp, is directed into the atomized solution. The radiation absorbed by the free atoms is measured at the wavelength specific to the element of interest. The resulting absorption is then compared with the absorption from known standards to quantify the elemental concentrations. FAAS requires an individual analysis for each element, and a large filter or several filters are needed to obtain the elemental concentrations at low- and trace-levels for up to 70 elements. Notable exceptions include $\mathrm{C}, \mathrm{S}$, and the halogens. On the other hand, GFAAS is able to achieve detection limits two orders of magnitude lower than FAAS (see Tab. 2.4-2) and requires much smaller sample sizes.

In addition to the IC and AC analysis of indoor air particles (as described in Section 2.4.2.2), Jones et al. (1999) analyzed for the metals $\mathrm{Ca}, \mathrm{Fe}, \mathrm{Pb}$, and $\mathrm{Zn}$ in particles collected onto segments of the same QMA filters. These filter segments were subjected to nitric acid and hydrogen peroxide pre-treatment prior to analysis by AAS for $\mathrm{Ca}$ and by GFAAS for $\mathrm{Fe}, \mathrm{Pb}$, and $\mathrm{Zn}$. The size-fractionated chemical composition (dia. $<1.1 \mu \mathrm{m}, 1.1<$ dia. $<2.1 \mu \mathrm{m}, 2.1<$ dia. $<10 \mu \mathrm{m}$ ) reported by the authors (Jones et al., 1999) for one roadside house is presented in Tab. 2.4-3.

Tab. 2.4-3 Ionic concentration analyzed by ionic chromatography and automated colorimetry and elemental concentration analyzed by atomic absorption spectrometry and graphite furnace atomic absorption spectrometry of size-fractionated indoor air samples from a roadside house (Jones et al., 1999)

\begin{tabular}{|c|c|c|c|c|c|c|c|c|}
\hline \multirow{2}{*}{$\begin{array}{l}\text { Instrumentation } \\
\text { Particle diameter } \\
(\mu \mathrm{m})\end{array}$} & \multicolumn{3}{|c|}{ IC $\left(\mu g m^{-3}\right)$} & \multirow{2}{*}{$\begin{array}{l}A C \\
\left(\mu g m^{-3}\right) \\
N H_{4}^{+}\end{array}$} & \multirow{2}{*}{$\begin{array}{l}\text { AAS } \\
\left(n g m^{-3}\right) \\
\mathrm{Ca}\end{array}$} & \multicolumn{3}{|c|}{ GFAAS (ng $\left.\mathrm{m}^{-3}\right)$} \\
\hline & $\mathrm{Cl}^{-}$ & $\mathrm{NO}_{3}^{-}$ & $\mathrm{SO}_{4}^{2-}$ & & & $P b$ & $\mathrm{Fe}$ & $Z n$ \\
\hline $0-1.1$ & $<0.1$ & $<0.1$ & 0.6 & 0.2 & $<$ d.l. $^{\text {a) }}$ & 5.3 & 30.5 & 2.6 \\
\hline $1.1-2.1$ & 0.4 & 0.1 & 0.1 & $<0.1$ & 13.1 & 2.4 & 92.6 & 1.2 \\
\hline $2.1-10$ & 0.1 & $<$ d.l. ${ }^{\text {a) }}$ & $<$ d.l. $^{\text {a) }}$ & $<0.1$ & 5.6 & $<0.1$ & 17.9 & 1.9 \\
\hline
\end{tabular}

a Detection limit. 


\subsubsection{Inductively Coupled Plasma Atomic Emission Spectrometry and Inductively Coupled Plasma Mass Spectrometry}

In general, for inductively coupled plasma atomic emission and or mass spectrometry (ICP/AES and ICP/MS) the samples are taken up in solution by extraction methods similar to those used for AAS, and it is a requirement that the solids are dissolved prior to introduction into the instrument. Solutions containing more than $10 \mathrm{~g} \mathrm{~L}^{-1}$ of dissolved solids are usually not analyzed by ICP/MS because of signal suppression or enhancement (Gerotto et al., 1995; Denoyer, 1992).

In ICP/AES, the dissolved sample is introduced into an atmosphere of argon gas seeded with free electrons induced by high voltage from a surrounding Tesla coil. The high temperatures in the induced plasma raise valence electrons above their normally stable states. When these electrons return to their stable states, a photon of light is emitted that is unique to the element, which was excited. This light is detected at specified wavelengths to identify the elements in the sample. ICP/AES acquires a large number of elemental concentrations using small sample volumes with acceptable detection limits for atmospheric samples.

As in the case of ICP/AES, the dissolved sample is introduced to the argon gas plasma producing monatomic positive ions. In ICP/MS, however, the ICP is in a horizontal configuration such that the ions are then directed into a mass spectrometer and detected according to their mass-to-charge ratio. The interface used to transport the ions from the hot plasma at atmospheric pressure into the mass spectrometer at very low pressure is a critical feature of the instrument. ICP/MS is an attractive option for the determination of ultra-trace elements in aerosols, providing simultaneous analysis of a wide range of elements at good sensitivity of the order of sub-ng g ${ }^{-1}$ (Thomas and Morawska, 2002; Thomas et al., 1997). As regards indoor environments, ICP-MS has been employed to analyze coarse $\left(\mathrm{PM}_{2.5-10}\right)$ particulate $\mathrm{Al}, \mathrm{Ca}, \mathrm{Fe}, \mathrm{K}, \mathrm{Mg}, \mathrm{S}$, and $\mathrm{Si}$ in a study of the indoor to outdoor relationships of fine and coarse particulate matter (Geller et al., 2002). The indoor fine and coarse particulate samples were collected in the living rooms of 13 homes with the USC Personal Particle Sampler, sampling at $5 \mathrm{~L} \mathrm{~min}^{-1}$, for $23 \mathrm{~h}$ sampling periods onto quartz substrates for coarse particulate ICP-MS analysis. The concentration ranges of the coarse particulate elements analyzed by ICP-MS reported for the indoor environments are presented in Tab. 2.4-4.

\subsubsection{Instrumental Neutron Activation Analysis}

For Instrumental Neutron Activation Analysis (INAA), the samples are often collected on cellulose filter substrates in high volume samplers. The aerosol samples can be measured non-destructively after very little sample preparation (Ondov and Divita, 1993; Olmez, 1989; Dams et al., 1970; Zoller and Gordon, 1970). INAA is technically non-destructive, but sample preparation may prevent the use of the sample for subsequent analyses by other methods since it renders the filter membrane brittle and radioactive. 
Tab. 2.4-4 Ranges of concentrations $\left(\mu \mathrm{g} \mathrm{m}^{-3}\right.$ ) of inorganic particles analyzed by INAA, ICP-MS, $X R F$, and PIXE for various size fractions reported in the literature for indoor environments.

\begin{tabular}{|c|c|c|c|c|c|}
\hline \multirow[t]{2}{*}{ Element } & \multirow{2}{*}{$\begin{array}{l}I^{\prime N A A^{a)}} \\
T S P\end{array}$} & \multirow{2}{*}{$\begin{array}{l}I C P-M S^{b)} \\
P M_{2.5-10}\end{array}$} & \multirow{2}{*}{$\begin{array}{l}X R F^{b)} \\
P M_{2.5}\end{array}$} & \multicolumn{2}{|l|}{$P I X E^{c)}$} \\
\hline & & & & $P M_{2.5}$ & $P M_{10}$ \\
\hline $\mathrm{Al}$ & & $0.01-0.35$ & $0-0.15$ & $0.007-0.388$ & $0.045-0.894$ \\
\hline As & $<0.1-1.0$ & & & & \\
\hline $\mathrm{Br}$ & 4-39 & & & $0.0007-0.0625$ & $0.003-0.065$ \\
\hline $\mathrm{Ca}$ & & $0.15-1.25$ & $0.02-0.17$ & $0.009-0.327$ & $0.186-1.281$ \\
\hline $\mathrm{Cd}$ & $4.0-37.9$ & & & & \\
\hline $\mathrm{Cl}$ & $0.5-10.1$ & & & $0.008-1.428$ & $0.053-2.402$ \\
\hline $\mathrm{Cu}$ & & & & $0.001-0.067$ & $0.002-0.124$ \\
\hline $\mathrm{Fe}$ & & $0.05-0.5$ & $0.01-1.4$ & $0.045-0.238$ & $0.115-0.719$ \\
\hline K & $<0.1-8.5$ & $0.01-0.17$ & $0-0.12$ & $0.209-3.749$ & $0.225-4.699$ \\
\hline $\mathrm{Mg}$ & & $0.01-0.18$ & & $0.008-0.120$ & $0.009-0.294$ \\
\hline $\mathrm{Mn}$ & & & & $0.002-0.023$ & $0.002-0.038$ \\
\hline $\mathrm{Na}$ & $0.4-3.6$ & & & $0.018-0.427$ & $0.022-1.367$ \\
\hline $\mathrm{Ni}$ & & & & $0.0009-0.007$ & $0.001-0.010$ \\
\hline $\mathrm{Pb}$ & & & & $0.008-0.201$ & $0.007-0.268$ \\
\hline $\mathrm{S}$ & & $0.02-0.36$ & $0-0.75$ & $1.036-6.414$ & $1.217-7.160$ \\
\hline $\mathrm{Sb}$ & $0.5-3.9$ & & & & \\
\hline $\mathrm{Si}$ & & $0.2-1.1$ & $0.1-0.41$ & $0.060-0.786$ & $0.174-2.661$ \\
\hline $\mathrm{Ti}$ & & & $0-0.15$ & $0.004-0.029$ & $0.005-0.212$ \\
\hline V & & & & $0.002-0.016$ & $0.003-0.024$ \\
\hline $\mathrm{Zn}$ & $0.02-0.30$ & & $0.002-0.014$ & $0.030-0.310$ & $0.048-0.435$ \\
\hline
\end{tabular}

a Reported by Landsberger and Wu (1995) for an indoor public smoking environment.

b Estimated from the figures of Geller et al. (2002).

c Reported by Chao and Wong (2002).

INAA basically involves irradiation of a filter sample with thermal neutrons for periods ranging from a few minutes to several hours. Bombardment with neutrons induces a nuclear reaction of the stable isotopes in the sample. The production of the radionuclide from the element is used to identify it and quantification is made possible by the use of prepared elemental standards. The amount of parent element in the sample can be determined since the intensity of these gamma rays is proportional to their number. The gamma-ray spectra are usually collected with a high-resolution germanium detector utilizing commercially available amplifiers and multi-channel analyzers.

One advantage of INAA is that it is not generally subject to interferences, unlike X-ray fluorescence (XRF) or particle-induced X-ray emission (PIXE), due to a much better ratio of gamma ray peak widths to total spectral width. However, INAA does not quantify some elements in particulate matter such as B, Be, C, $\mathrm{Cd}, \mathrm{Hg}, \mathrm{Li}, \mathrm{N}, \mathrm{Ni}, \mathrm{O}, \mathrm{P}, \mathrm{Pb}, \mathrm{S}, \mathrm{Si}, \mathrm{Sn}$ and $\mathrm{Tl}$ because of their poor sensitivity. In addition, a major drawback is the long counting time required to quantify a large elemental range. However, by using the techniques of epithermal neutron irradia- 
tion in conjunction with Compton suppression, Landsberger and Wu (1995) lowered the detection limits of $\mathrm{Cd}$, As, and $\mathrm{Sb}$ measurements to $2 \mathrm{ng}$ for $\mathrm{Cd}, 0.2 \mathrm{ng}$ for As, and $0.03 \mathrm{ng}$ for $\mathrm{Sb}$. The researchers analyzed these metals in particulate material in indoor public smoking environments. The particles were sampled on Teflon filters for periods of $4-10 \mathrm{~h}$ at flow rates of $5 \mathrm{~L} \mathrm{~min}^{-1}$. Elements including $\mathrm{Br}, \mathrm{Cl}, \mathrm{Na}, \mathrm{K}$, and $\mathrm{Zn}$ were found at elevated levels (see Tab. 2.4-4).

\subsubsection{X-ray Fluorescence}

For X-ray fluorescence (XRF), a uniform aerosol distribution on a thin filter substrate is required (e.g. collected by total filter samplers, stacked filter units, or dichotomous samplers). The filters are necessarily thin, such as nucleopore filters, because very thick filters or thick particle deposits on filter substrates scatter the excitation protons and lower the signal-to-noise ratio for PIXE. X-ray analysis methods, such as PIXE and XRF, require particle size diameter corrections (for low atomic number targets such as those typical in indoor aerosol studies) for spherical particles and large particles (typically particles with aerodynamic diameters $>2.5 \mu \mathrm{m}$ ) because of their ability to absorb X-rays (Dzubay and Stevens, $1975)$.

XRF (Dzubay and Stevens, 1975) employs high-energy X-rays that eject innershell electrons from the atoms of each element in the irradiated filter sample. Inner-shell vacancies are generated by the electromagnetic radiation and filled by higher energy electrons of the elements analyzed. A fluorescent X-ray photon is released producing a characteristic X-ray. The energy of this photon is unique to each element, and the number of photons is proportional to the concentration of the element. Concentrations are quantified by comparing photon counts for a sample with those obtained from thin-film standards of known concentration. Various XRF methods exist that are variants of the basic process. They can be broadly divided into two categories: Wavelength Dispersive X-ray Fluorescence (WDXRF), involving crystal diffraction for the observation of fluorescent X-rays, and Energy Dispersive X-ray Fluorescence (EDXRF), which uses a silicon semiconductor detector.

$\mathrm{XRF}$ analyses of fine particulate $\mathrm{Al}, \mathrm{Ca}, \mathrm{Fe}, \mathrm{K}, \mathrm{S}, \mathrm{Si}, \mathrm{Ti}$, and $\mathrm{Zn}$ have been reported for indoor environments in the study of the indoor to outdoor relationships of fine and coarse particulate matter in southern California (Geller et al., 2002). The indoor fine particulate samples were collected in the living rooms of 13 homes with the USC Personal Particle Sampler, sampling at $5 \mathrm{~L} \mathrm{~min}^{-1}$, for $23 \mathrm{~h}$ sampling periods onto Teflon filters for the XRF analyses. The concentration ranges of the fine particulate elements reported for the indoor environments are presented in Tab. 2.4-4. 


\subsubsection{Particle-Induced X-Ray Emission}

PIXE is another form of elemental analysis based on the characteristics of X-rays and the nature of X-ray detection (Cahill, 1980; Cahill et al., 1987); the sample collection and preparation procedures are the same as those for XRF.

PIXE uses beams of energetic ions, consisting of protons at an energy level of 2 to $5 \mathrm{MeV}$ (mega-electron-volt), to create inner electron shell vacancies. As outer electrons fill inner electron shell vacancies, the emitted characteristics of X-rays can be detected by wavelength dispersion (which is scattering from a crystal) or by energy dispersion (which involves direct conversion of X-rays). The development of focusing energetic proton beams (proton microprobes) has expanded the application of PIXE from environmental and biological sciences to geology and material sciences. PIXE analysis is often used for impactor samples or small filter substrates, since proton beams can be focused to a small area with no loss of sensitivity (Cahill and Wakabayashi, 1993).

PIXE analysis can provide information on a wide range of elements typically found in airborne particles in an indoor environment, such as $\mathrm{Al}, \mathrm{Br}, \mathrm{Ca}, \mathrm{Fe}, \mathrm{K}$, $\mathrm{Mg}, \mathrm{Na}, \mathrm{Ni}, \mathrm{Pb}, \mathrm{S}, \mathrm{Si}, \mathrm{Ti}, \mathrm{V}$, and $\mathrm{Zn}$ (see Chao and Wong, 2002). However, attempts to improve the sensitivity of PIXE analysis may result in damage to Teflon-membrane filters. Developments (Malm et al., 1994) using PIXE analysis at moderate sensitivity plus single-anode XRF analysis at high sensitivity for transition/heavy metals have achieved minimum detectable limits of less than $0.01 \mathrm{ng} \mathrm{m}^{-3}$. The concentration ranges of elements analyzed by PIXE in the $\mathrm{PM}_{2.5}$ and $\mathrm{PM}_{10}$ size fractions sampled for $96 \mathrm{~h}$ through cyclones onto Teflon filters at $5 \mathrm{~L} \mathrm{~min}^{-1}$, as reported by Chao and Wong (2002) for indoor environments in Hong Kong, are provided in Tab. 2.4-4.

\subsubsection{Summary}

It can be seen that no single instrument can measure all chemical species. The account of methods for the analysis of inorganic particles presented here is by no means meant to be exhaustive, and it should be noted that improvements in techniques for the analysis of inorganic particles in air appear regularly in the literature. An example is instrumentation developed for Continuous Emission Monitoring (CEM) of metal aerosols in air with no sample pre-treatment stage (Lemieux et al., 1998; Gomes et al., 1996). Although developed for the analysis of outdoor air, these instrumental techniques for the purpose of real-time monitoring of elemental composition of aerosols in theory offer an effective way of monitoring pollutants in outdoor and indoor air.

\section{4 .3}

\section{Analysis of Biological Particles}

\subsubsection{Sampling of Biological Particles}

The biological fraction of airborne particles or settled dust indoors consists mainly of bacteria, viruses, fungal spores, pollen, human and animal dander, and other 
traces of microbial and biological material. Their natural sources are soil, plants, and animals, from which air currents and winds may resuspend them. Outdoor air is an important source of biological particles found in the indoor environment. Other sources of biological particles indoors are derived from the day-to-day activities of man and his animals, for example, handling of organic material like firewood, houseplants or vegetables. Biological particles that have settled indoors, along with other particulate matter, may become resuspended into the ambient air through normal household activities and other mechanical disturbances.

Biological agents may also increase their numbers in the indoor environment. House dust mites proliferate in damp indoor conditions, i.e., when the relative humidity $(\mathrm{RH})$ is greater than $45 \%$ (Arlian, 1999). Microbes such as bacteria and fungi grow and increase their numbers wherever there is moisture available, either due to normal conditions (e.g. wet surfaces in bathrooms) or due to undesired moistening of materials or structures. This may be caused by acute incidents such as flooding, leaks, or condensation leading to moisture or water damage. Microbial growth in a building may be a source of biological particles or chemical emissions into the indoor air (Gorny et al., 2002; Batterman, 1995). Such microbial growth related to dampness or moisture damage is strongly associated with respiratory health disorders, as has been shown in many epidemiological studies (Brunekreef et al., 1989; Dales et al., 1991a,b).

Bioaerosol sampling may be needed for many different purposes. The aim of the investigation may be exposure assessment for cases of building-related illness and/ or detection of indoor-related sources of contamination. Concentrations of biological particles vary greatly in time and space (Hyvärinen et al., 2001), and short-time sampling may not necessarily reflect this variation properly. Therefore, sampling of settled dust, regarded as a time-integrated sample, is sometimes used for the determination of biological agents in indoor environments. However, the techniques for sampling settled dust add to the available range for sampling indoor environments, but do not replace air sampling (Chew et al., 2001; Lioy et al., 2002).

Sampling of airborne biological particles, or bioaerosols, is generally based on the same principles as those for particle collection from air. However, microbial cells or other biological material to be sampled may be vulnerable in terms of viability and cell integrity (viable cells) or biological activity, as is the case for endotoxin determination (Reponen et al., 2001). Thus, specific needs for collection techniques, sampling times, and sample handling must be fulfilled when sampling biological material from air. Aseptic techniques, i.e., systematic avoidance of sample contamination, must be used throughout the sampling procedures, transportation, and laboratory analyses.

The sampling devices most commonly used for bioaerosol sampling are inertial impactors (multiple-hole or slit samplers), centrifugal samplers, cyclones, liquid impingers, and filter samplers (Willeke and Macher, 1999). Some impactors are combined with culture medium, and the collected particles are impacted directly onto the medium surface (e.g. 1-, 2-, and 6-stage Andersen impactors, surface air samplers), or the sample is collected on to a glass slide or adhesive tape as a collection surface. Some samplers use centrifugal impaction such as the Reuter Centrifugal 
samplers (RCS and RCS+). While these samplers are usually combined with culture methods or direct microscopic counting for analytical techniques, liquid impingement (e.g. AGI-4, AGI-30) or its application using viscous collection liquid (e.g. BioSampler) (Lin et al., 1999) can be combined with a larger array of analytical techniques, which include biochemical or immunochemical tests or bioassays. Bioaerosol particles may also be collected with filters, usually either capillary pore filters or porous membrane filters, which allows either direct counting after appropriate staining, or various analyses after eluting the sample into a liquid.

The cut-off sizes of bioaerosol samplers vary from $0.3 \mu \mathrm{m}$ to $6.6 \mu \mathrm{m}$ (Willeke and Macher, 1999). In order to efficiently collect the bioaerosol particles of interest, it would be important to know their size range. Many allergen and microbial particles, such as mite, cat, and dog allergens, bacterial cells, and fungal spores are in the size range of $1-10 \mu \mathrm{m}$, and are effectively collected by many commonly used samplers. On the other hand, it has been shown that microbial growth on building material also emits large numbers of particles smaller than whole spores, the so-called 'microbial fragments' (Gorny et al., 2002). It has been shown that these fragments, which are less than $1 \mu \mathrm{m}$ in diameter, carry similar antigen characteristics as whole spores (Gorny et al., 2002), but their importance as exposing agents is as yet little known, and specific sampling techniques for these fragments have not yet been validated. More comprehensive overviews of the devices and sampling aspects of bioaerosol sampling are presented in Reponen et al. (2001) and Willeke and Macher (1999).

\subsubsection{Analysis of Biological Properties}

The total proportion of biological particles in the particulate fraction of ambient or indoor air is not well known, but it probably varies according to climatic and other conditions. It has been reported that the fungal and bacterial particles in indoor air only comprise less than $1 \%$ of the total mass of airborne particles (Toivola et al., 2002). However, the health importance of biological particles is remarkable due to their allergenic and immunotoxic potentials. For example, pollen fragments, animal dander, and mite excreta contain components that are among the most important allergens of the living environment. Endotoxin, a cell wall component of all gramnegative bacteria, has high immunotoxic potential, and a similar but lower potential is shown by $\beta$-(1 $\rightarrow 3)$-glucan, which is the corresponding component of fungal cells. Many microbial cells, such as fungal spores and bacteria, present in indoor environments, have been shown to have similar immunotoxic potential. In this respect, they have been shown to induce production of pro-inflammatory markers such as NO, interleukins, and tumor necrosis factor $a(\mathrm{TNF} a)$ both in vitro and in vivo (Hirvonen et al., 1997; Huttunen et al., 2000; 2002; Jussila et al., 2001; 2002). This immunotoxic potential is of the same order of magnitude as that reported for anthropogenic particulate matter such as diesel exhaust particles (Hälinen et al., 1999). Many indoor microbes also exhibit cytotoxic properties.

Fungal and bacterial growth produces products of microbial metabolism, e.g. microbial volatile organic compounds (MVOC), which give rise to the characteris- 
tic odors of 'mold' or 'cellar' (Bjurman, 1991). Being easily volatile, MVOCs can be determined in air by collecting the sample into an adsorbent, followed by thermodesorption and analysis by gas chromatography/mass spectrometry (Batterman, 1995). Under conditions of insufficient nutrition or in the presence of competing microbes, many fungi and bacteria also produce acutely toxic secondary metabolites (i.e. mycotoxins and bacterial toxins). The mycotoxins of the fungi Stachybotrys, Aspergillus versicolor, Fusarium, Trichoderma, and Chaetomium are examples of extremely toxic fungal metabolites (Gravesen et al., 1994; Nielsen et al., 2001). Among the bacteria, toxic secondary metabolites are produced by Streptomyces, Nocardiopsis, and Bacillus (Andersson et al., 1997, 1998; Peltola et al., 2001). Microbial toxins are non-volatile, but they can be attached to the fungal spores found in indoor environments (Sorenson et al., 1987). In addition, mycotoxins have been detected in moldy building materials (Nielsen et al., 1998, 1999; Tuomi et al., 2000) and in the dust of ventilation ducts (Smoragiewicz et al., 1993). When sampled, mycotoxins can be determined by chromatographic methods, such as thin-layer chromatography, gas chromatography/mass spectrometry, and high-performance liquid chromatography (Nielsen and Thrane, 2001; Tuomi et al., 2001).

The toxicity of indoor-related microbes may depend on the material on which the organism is growing. Thus, microbial substrates play a role in regulation of the secondary metabolism (Murtoniemi et al., 2001; Roponen et al., 2001). Although the importance of microbial metabolites in health risk assessment is not yet fully known, they must be considered as potentially relevant indoor contaminants due to their cytotoxic capacity (Pitt et al., 2000).

The diversity of various biological agents is large and the concentrations of most individual agents are low. In practice, extensive detection or monitoring of individual agents may be beyond the resources available for building investigations and only the main microflora and the most common allergens are usually determined from the samples of indoor air or house dust. Depending on the purpose of the studies, non-culture methods for quantifying the components of the biomass or characterizing the microbial communities in the sample of particle material can also be used. Indirect methods to show the biological activity, either specific such as endotoxin activity, or non-specific, such as cytotoxicity of the dust, can be used for further characterization of the biological fraction or indoor particulate matter.

\subsubsection{Culturing Methods for Viable Fungi and Bacteria}

Once a sample of environmental microbes has been obtained from the indoor air or the house dust (see Section 2.4.3.1), the presence of major groups of environmental microbes, fungi, and bacteria can be detected by culturing the sample under suitable growth conditions in a laboratory. Culturable fungi and bacteria comprise approximately $1 \%$ of all microbial particles in most environments (Toivola et al., 2002). This is because many of the spores and cells are damaged, dead or otherwise non-culturable, i.e. unable to grow into colonies under the given conditions, following collection of an air or dust sample. Nevertheless, counts of viable 
microbes in both air and house dust have been used to characterize the indoor air quality or to estimate the microbial exposures in different settings.

In terms of culturing viable microbes, microbial genera and species are selected by the media and growth conditions, such as temperature and competitive interactions. Most fungi relevant in indoor environments can be cultured on $2 \%$ malt extract agar at room temperature (Samson et al., 1994). For xerophilic fungi with lower water activity $\left(\mathrm{a}_{\mathrm{w}}\right)$ demands, another medium, known as DG18, has been recommended. For monitoring indoor bacteria, tryptone-yeast-glucose agar or tryptone-soya-agar is suitable (Samson et al., 1994). By further adjustment of the growth medium and conditions, even less commonly occurring species may be detectable. An example of a bacterial group that are not detected with ordinary growth media and under standard growth conditions are the atypical mycobacteria, belonging to the genus Mycobacterium. Many of the mycobacterium species are slow growing, requiring more than seven days for incubation and sometimes even several months. Their detection is based on a decontamination protocol that involves a treatment that eliminates most of the other microbes, followed by subsequent culturing on a specific medium, such as Middle brook agar or egg medium adjusted to low $\mathrm{pH}$ (5.5-6.5) (Katila et al., 1989).

Identification of the common fungal genera or species is mainly based on morphological analysis by microscopy. Further characterization of the isolates to species level requires culturing on different media and expertise in environmental mycology. For bacterial colonies, the identification is based on gram staining and various biochemical and physiological tests for the isolated organism (Holt, 1984). Chemotaxonomic and genetic methods may also be employed for identification. For overviews of culturable methods, see also Burge and Otten (1999), Macher et al. (2001) and Reponen et al. (2001).

\subsubsection{Direct Microscopic Methods}

Numbers of microbial or pollen particles can be counted directly from an air sample collected on a filter, glass slide or other collection surface. The counting can be facilitated by light, scanning electron or epifluorescence (staining with fluorescent dye, acridine orange) microscopy. Using these methods, differentiation of fungal spores and bacteria is based on their size $(2-10 \mu \mathrm{m}$ for fungal spores and less than $2 \mu \mathrm{m}$ for bacterial cells). The use of light microscopy allows a rough assessment of the fungal types involved. With the aid of scanning electron microscopy, an experienced investigator can identify fungal genera or species by the appearance of spore surfaces and the spore-forming structures.

Direct counting is best suited for environments with high microbial concentrations, since indoor concentrations of microbial particles may be near the detection limit of the method. Since the counting is based on subjective assessment, the repeatability of the counting may need careful consideration; Eduard et al. (2001) have discussed aspects of counting precision and its estimation. Microscopic counting may be assisted by image analysis (Morris, 1995). Image analysis techniques have mainly been applied for purposes of biotechnology, focusing on charac- 
terization of the morphology of the colony or mycelium of the organism of interest (Sandor et al., 2001; Yang et al., 2001). Applications to more complex matrices are thus far scarce. Thrane et al. (2001) have reported a method for species differentiation of the fungus Trichoderma from building material and dust samples by image analysis of the gas chromatograms of the cultured extracts.

\subsubsection{Immunological Methods}

Specific biological components of dust or particulate material can be identified from house dust or samples of airborne particles by the use of immunoassays. Immunoassays are generally applied to allergen analyses. The main sources of allergens in the indoor environment are cat, dog, house dust mite, cockroach and other insects, fungi, and pollen. Direct measurements of allergen concentrations from air samples may be difficult due to the low concentrations of individual allergens. Therefore, vacuuming floors, beds or furniture is often used for the collection of allergen samples. The detection of allergens in environmental samples is based on the specific reaction between an antigen and antibody, usually determined by the ELISA (enzyme-linked immunoabsorbent assay) method (Macher et al., 1999). Samples of sieved dust are extracted, and, for example, cat or dog allergens (Fel $d 1$ or Can $f 1$, respectively) are determined using monoclonal antibodies (Rose, 1999; Karlsson et al., 2002; Leaderer et al., 2002). Pollen allergens can also be detected in house dust (Fahlbusch et al., 2001), although there are few published reports about pollen allergens in indoor environments.

\subsubsection{Chemical Markers of Microbial Biomass}

Quantification methods for microorganisms that are based on cultivation of microbes invariably underestimate the actual amount of microbes present. All culture media are selective (see Section 2.4.3.2) and favor the growth of those microbes for which the nutrient and $\mathrm{pH}$ conditions are suitable. Furthermore, only a few percent of environmental microbes are culturable in the laboratory. However, even dead or non-culturable cells may contain bioactive components that are of interest from the point of view of exposure assessment or health effects studies. Therefore, methods to assess the total microbial biomass from environmental samples are needed. Various fractions of microbial biomass in the dust can be determined through their chemical markers. One type of such biomarkers are the 3-hydroxy fatty acids that determine the presence of lipopolysaccharide (LPS, endotoxin), which is characteristic of gram-negative bacteria (Szponar and Larsson, 2001). Muramic acid is a chemical marker of peptidoglycans, structural components common to all bacteria (Saraf and Larsson, 1996). Ergosterol is a sterol that can be used as a chemical marker of filamentous fungi (Flannigan, 1997; Miller and Young, 1997). Yeasts, which also belong to the common micro-fungi of indoor environments, contain less ergosterol, and thus they are underestimated in this determination method of fungal biomass. Gas chromatography/mass spectrometric methods may be applied for the determination of the chemical markers (Saraf et al., 1997, 1999). 


\subsubsection{Genetic Methods}

DNA-based methods, such as PCR (polymerase chain reaction) techniques, can be used for the detection of specific agents, such as a microbial genus or species (Haugland et al., 1999; Buttner et al., 2001; Cruz-Perez et al., 2001; Rintala et al., 2002). Although the methods are still under development for field purposes, their specificity and independence of the viability of the organism make the DNA-based methods a promising tool for the future.

\subsubsection{Other Methods to Detect Biological Material}

All gram-negative bacteria contain endotoxin in their cell wall, which can be specifically determined by means of the Limulus bioassay. The endotoxin content of house dust or airborne particles can be quantitatively assessed as biological activity using this assay (Milton, 1999). The endotoxin content is expressed in terms of endotoxin units, EU; equivalent to $0.1 \mathrm{ng}$ of reference standard endotoxin. Since this assay is based on biological activity, it does not give a concentration of any single substance. For the same LPS component, there is also a chemical marker, i.e. 3-hydroxy fatty acids (see Section 2.4.3.6), which can be used as a quantitative determination method (Szponar and Larsson, 2001). Since the Limulus test measures the biological activity, and determination of 3-hydroxy fatty acids reveals the presence (not bioactivity) of LPS, the results obtained by the two methods do not necessarily fully agree (Saraf et al., 1997; Hines et al., 2000).

A modification of the Limulus bioassay can also be used for the determination of $\beta$ - $(1 \rightarrow 3)$ glucans, which are glucose polymers occurring in most fungi, some bacteria, and plants. Both endotoxin and glucan analyses can be used to assess the microbial content of dust, and due to their immunological potential (Rylander et al., 1998) they have been suggested to be possible causal agents of symptoms associated with microbial aerosols.

While house dust or airborne particulate material often contains many types of biologically active agents, the determination of overall biological activity of the crude sample by means of in vitro tests provides a means for comparing different indoor conditions. Many cell types can be used for such tests, mammalian cells being better models for possible health effects than microbial cells. A possible link to the human responses can be obtained, since the same parameters can be measured from both humans and in a test system using cell culture. Biological activity can be measured, for example, as induction of inflammatory responses or as cytotoxicity in vitro.

Mouse macrophages are an example of a useful model for the assessment of biological activity of airborne particulate matter. Personal samples $(24 \mathrm{~h})$ were collected from 81 persons in order to compare personal exposure to particles with the concentrations observed by fixed-site sampling (Roponen et al., 2003). Biological activity of the collected filter samples was measured as the ability to induce production of pro-inflammatory mediators in this in vitro system, and the same mediators were measured from nasal lavage samples of the studied individuals. The same parameters could be detected in both types of samples, and although 
the cytokine levels did not correlate with each other, they allowed discrimination between individuals with 'high' and 'low' microbial exposure. The results suggest that this is a relevant way of describing the potential of airborne particles to induce such responses in humans.

Other types of in vitro systems can also be used. For example, human epithelial cells have been used to measure induction of interleukin- 6 and interleukin-8 production by house dust samples. Elevated levels of these inflammatory markers were observed with house dust, while swine dust or pure endotoxin gave no such response (Saraf et al., 1999). THP-1 monocytic cell line has been suggested as another sensitive bioassay and potential screening tool for hazard evaluation of settled dust in the indoor environment (Allerman and Poulsen, 2002). These methods are under development and need more validation, but preliminary results have been promising.

Biological material, such as bacteria or microbial toxins, may also be detected by fluorescence or chemiluminescence means, or with biosensors which employ combined techniques of different kinds (Angell et al., 1993; Wittwer et al., 1997; Carlson et al., 2000; Goh et al., 2002; Yacoub-George et al., 2002; Rotman et al., 2003). Most of these advanced methods, originally developed for bacterial detection in the food industry or medicine, are aimed at rapid detection without culturing the organism. These techniques will probably have important applications in the detection of airborne biological agents as well.

\subsubsection{Bioterrorism}

In today's world, bioaerosol detection may also mean detection of contagious or toxic agents spread purposefully into the environment. Among the biohazardous agents potentially usable for bioterrorism are spores of Bacillus anthracis (causative agent of anthrax) and the non-spore forming gram-negative bacterium Yersinia pestis (causative agent of the plague). Among potential agents are also mycotoxins or bacterial toxins, which have acutely toxic effects when inhaled or ingested.

Special detection devices have been developed for these agents based on molecular or immunochemical techniques for the rapid and specific detection of hazardous microbes. They are specifically developed for use under field conditions. Rapid detection methods are often modifications of PCR techniques (Handheld Advanced Nucleic Acid Analyzer, HANAA) or are combined with flow-cytometry using specific antibodies (Autonomous Pathogen Detection System). Based on the very specific PCR detection, the investigator must decide beforehand what agents to look for and set the device accordingly, although techniques are being developed to further increase the number of detectable agents. These techniques use very small volumes of the sample and reagents, thus allowing a rapid result (minutes instead of hours), a key aspect in this type of bioaerosol monitoring. On the other hand, technologies developed for purposes of defence and bioterrorism control will eventually find more applications in civil use as well. Evidently, more development work is needed for applications for non-pathogenic environmental microbes which have large diversity, and which may occur in high concentrations, creating a complex matrix for the individual organisms to be detected. 
While the technologies aiming at detection of biohazardous agents are not always published in the common scientific literature, more information can be obtained through the Internet, e.g.: http://www.nap.edu/html/terrorism/ch6.html

\subsubsection{Summary}

Sampling methods of bioaerosols are most often based on impaction on agar medium, microscopic slide or filter, or on collection by impingement into a buffer solution or viscous liquid. While the principles of the collection methods are very similar to those for particles, the biological aspect of bioaerosols sets special demands for the detection and analysis phases. Once the particle sample has been collected, the biological particles can be detected by methods based on the cultivation of microbes, by bioassays, or by chemical, immunochemical or genetic analyses. For specific microbes, on-line detection methods have also been developed.

The biological components found in the particulate fraction of indoor air include bacteria, viruses, fungal spores, pollen, human and animal dander, and traces of microbial, plant or animal material. The total proportion of these biological particles usually comprises less than $1 \%$ of the total mass of airborne particulate matter in the indoor environment. Nevertheless, their impact on human health is considerable due to their allergenic (e.g. pollen fragments, animal dander, and mite excreta), immunotoxic (e.g. endotoxin, $\beta$-(1 $\rightarrow 3$ )-glucan), and cytotoxic (e.g. mycotoxins and bacterial toxins) potentials. A wide variety of complementary microscopic, immunological, chemical, spectroscopic, and genetic methods exist that enable researchers to characterize the quantitative and qualitative content of the biological aerosols. In addition, bioassays and immunoassays facilitate the determination of the biological activity of ambient air or unsettled dust from indoor environments.

\section{References}

Allerman, L.; Poulsen, O. M. (2002) Interleukin-8 Secretion from Monocytic Cell Lines for Evaluation of the Inflammatory Potential of Organic Dust. Environmental Research, 88, 188-198.

Andersson, M.A.; Nikulin, M.; Koljalg, U.; Andersson, M.C.; Rainey, F.; Reijula, K.; Hintikka, E. L.; Salkinoja-Salonen, M.S. (1997) Bacteria, Moulds and Toxins in Water-Damaged Building Materials. Applied and Environmental Microbiology, 63, 387-393.

Andersson, M. A.; Mikkola, R.; Helin, J.; Andersson, M.C.; SalkinojaSAlonen, M.S. (1998) A Novel Sensitive Bioassay for Detection of Bacillus Cereus Emetic Toxin and Related Depsipeptide Ionophores. Applied and Environmental Microbiology 64, 1338-1343.

Angell, P.; Arrage, A.A.; Mittelman, M.W.; White, D.C. (1993) On-line, Non-destructive Biomass Determination of Bacterial Biofilms by Fluorometry. Journal of Microbiological Methods 18, 317-327.

Arlian, L. G. (1999) House Dust Mites. In: Macher, J.; Ammann, H.; Burge, H.; Milton, D. K.; Morey, P. R. (Eds.): Bioaerosols - Assessment and Con- 
trol, American Conference of Governmental Industrial Hygienists, Cincinnati, $\mathrm{OH}, 1-9$.

Batterman, S. (1995) Sampling and Analysis of Biological VOCs. In: Burge, H.A. (Ed.) Bioaerosols. CRC Press, Boca Raton, 249-268.

BéruBÉ, K. A.; Jones, T. P.; Williamson, B. J. (1997) Electron Microscopy of Urban Airborne Particulate Matter. Microscopy and Analysis 61, 11-13.

BéruBÉ, K. A.; Jones, T. P.; Williamson, B. J.; Richards, R. J. (1997) Characterization of Soot: Surface and Internal Properties. Respiratory Medicine 91, p. 81.

BéruBé, K. A.; Jones, T.P.; Williamson, B.J.; Winters, C.; Morgan, A.J.; Richards, R. J. (1999) Physicochemical Characterization of Diesel Exhaust Particles: Factors for Assessing Biological Activity. Atmospheric Environment 33, 1599-1614.

BéruBÉ, K. A.; Richards, R. J. (2001) Physicochemical Identification and Comparative Biopersistence of Indoor and Outdoor Airborne Particulate Matter: A Final Report prepared for DEFRA, Cardiff, UK.

BÉRuBÉ, K. A. (2003) Unpublished data, School of Biosciences, Cardiff University, Wales, UK.

Brunekreef, B.; Dockery, D. W.; Speizer, F.E.; Ware, J.H.; Spengler, J.D.; FerRIs, B. G. (1989) Home Dampness and Respiratory Morbidity in Children. American Review Respiratory Disease 140, 1363-1367.

Burge, H. A.; Otten, J.A. (1999) Fungi. In: Macher, J. M.; Ammann, H.A.; Burge, H.A.; Milton, D. K.; Morey, P. R. (Eds.) Bioaerosols - Assessment and Control. American Conference of Governmental Industrial Hygienists (ACGIH), Cincinnati, OH, 1-13.

Burnstock, A.; Jones, C. (2000) Scanning Electron Microscopy Techniques for Imaging Materials from Paintings. In: CReAGH, D. C.; BRADLEY, D.A. (Eds.): Radiation in Art and Archeometry. Elsevier, London, 202-231.

Buttner, M. P.; Cruz-Perez, P.; Stetzenbach, L. D. (2001) Enhanced Detection of Surface-Associated Bacteria in Indoor Environments by Quantitative PCR. Applied and Environmental Microbiology 67, 2564-2570.

Bjurman, J. (1999) Release of MVOCs from Microorganisms. In: SalthamMER, T. (Ed.) Organic Indoor Air Pollutants: Occurrence - Measurement Evaluation. Wiley-VCH, Weinheim, 259-273.

Cahill, T. A. (1980) Proton Microprobes and Particle-Induced X-ray Analytical Systems. Annual Review Nuclear Particle Science 30, 211-252.

Cahill, T. A.; Feeney, P. J.; Eldred, R.A. (1987) Size-Time Composition Profile of Aerosols Using the Drum Sampler. Nuclear Instrumentation and Methods in Physics Research B22, 344-348.

Cahill, T. A.; WaKabayashi, P. (1993) Compositional Analysis of Size-Segregated Aerosol Samples. In: Newman, L. (Ed.) Measurement Challenges in Atmospheric Chemistry. Advances in Chemistry Series No. 232, American Chemical Society, Washington D.C., 211-228.

Carison, M.A.; Bargeron, C. B.; Benson, R. C.; Fraser, A. B.; Phillips, T. E.; Velky, J.T.; Groopman, J.D.; Strickiand, P.T. (2000) An Automated, Handheld Biosensor for Aflatoxin. Biosensors \& Bioelectronics 14, 841-848.

Chao, C.; Wong, K. K. (2002) Residential Indoor $\mathrm{PM}_{10}$ and $\mathrm{PM}_{2.5}$ in Hong Kong and the Elemental Composition. Atmospheric Environment 36, 265277.

Chew, G. L.; Douwes, J.; Doekes, G.; Higgins, K. M.; van Strien, R.; Spithoven, J.; Brunekreef, B. (2001) Fungal Extracellular Polysaccharides, beta$(1 \rightarrow 3)$-Glucans and Culturable Fungi in Repeated Sampling of House Dust. Indoor Air 11, 171-178. 
Claes, M.; Gysels, K.; Van Grieken, R.; Harrison, R. M. (1998) Inorganic Composition of Atmospheric Aerosols. In: Harrison, R. M.; VAN Grieken, R. (Eds.): Atmospheric Particles. John Wiley and Sons Ltd., Chichester, 96-136.

Cruz-Perez, P.; Buttner, M.P.; Stetzenbach, L. D. (2001) Specific Detection of Stachybotrys chartarum in Pure Culture Using Quantitative Polymerase Chain Reaction. Molecular and Cellular Probes 15, 129-138.

Dales, R. E.; Zwanenburg, H.; Burnett, R.; Franklin, C. A. (1991a) Respiratory Health Effects of Home Dampness and Molds Among Canadian Children. American Journal of Epidemiology 134, 196-203.

Dales, R. E.; Burnett, R.; ZwanenburG, H. (1991b) Adverse Health Effects Among Adults Exposed to Home Dampness and Molds. American Reviews of Respiratory Disease 143, 505-509.

Dams, R.; Robbins, J.A.; Rahn, K.A.; Winchester, J.W. (1970) Non-Destructive Neutron Activation Analysis of Air Pollution Particulates. Analytical Chemistry 42, 861-867.

Denoyer, E. R. (1992) Semiquantitative Analysis of Environmental Materials by Laser Inductively Coupled Plasma Mass Spectrometry. Journal Analytical Atomic Spectroscopy 7, 1187-1193.

Dzubay, T. G.; Stevens, R. K. (1975) Ambient Air Analysis with Dichotomous Sampler and X-ray Fluorescence Spectrometer. Environmental Science and Technology 9, 663-668.

Eduard, W.; Blomquist, G.; Nielsen, B. H.; Heldal, K. K. (2001) Recognition Errors in the Quantification of Microorganisms by Fluorescence Microscopy. Annals of Occupational Hygiene 45, 493-498.

Fahlbusch, B.; Hornung, D.; Heinrich, J.; Jager, L. (2001) Predictors of Group 5 Grass-Pollen Allergens in Settled House Dust: Comparison Between Pollination and Non-Pollination Seasons. Allergy 56, 1081-1086.

Flannigan, B. (1997) Air Sampling for Fungi in Indoor Environments. Journal of Aerosol Science 28, 381-392.

Geller, M.; Chang, M.; Sioutas, C.; Ostro, B.; Lipsett, M. (2002) Indoor/ Outdoor Relationship and Chemical Composition of Fine and Coarse Particles in the Southern California Deserts. Atmospheric Environment 36, 1099-1110.

Genfa, Z.; DAsGupta, P. K. (1989) Fluorometric Measurement of Aqueous Ammonium Ions in a Flow Injection System. Analytical Chemistry 61, 408412.

Gerotto, M.; Dell'Andrea, E.; Bortoli, A.; Marchiori, M.; Palonta, M.; Troncon, A. (1995) Interference Effects and their Control in ICP-MS Analysis of Serum and Saline Solutions. Microchemistry Journal 51, 73-87.

GoH, Y. Y.; Ho, B.; Ding, J. L. (2002) A Novel Fluorescent Protein-Based Biosensor for Gram-Negative Bacteria. Applied and Environmental Microbiology 68, 6343-6352.

Gomes, A. M.; Sarrette, J. P.; Madon, L.; Almi, A. (1996) Continuous Emission Monitoring of Metal Aerosol Concentrations in Atmospheric Air. Spectrochimica Acta 51, 1695-1705.

Gorny, R. L.; Reponen, T.; Willeke, K.; Schmechel, D.; Robine, E.; BoisSier, M.; Grinshpun, S.A. (2002) Fungal Fragments as Indoor Air Biocontaminants. Applied and Environmental Microbiology 68, 3522-3531.

Gravesen, S.; Frisvad, J.C.; Samson, R.A. (1994) Microfungi, 1st ed. Munksgaard, Copenhagen, Denmark.

Hälinen, A. J.; Komulainen, H.; Salonen, R. O.; Ruotsalainen, M.; HinvoNEN, M.-R. (1999) Diesel Particles Induce Nitric Oxide Production in Murine Alveolar Macrophages and Rat Airways. Environmental Toxicology and Pharmacology 7, 11-18. 
Haugland, R. A.; Vesper, S. J.; Wymer, L. J. (1999) Quantitative Measurement of Stachybotrys chartarum conidia Using Real-Time Detection of PCR Products with the TaqMan Fluorogenic Probe System. Molecular and Cellular Probes, 13, 329-340.

Hines, C. J.; Milton, D. K.; Larsson, L.; Petersen, M.R.; Fisk, W. J.; MenDELL, M. J. (2000) Characterization and Variability of Endotoxin and 3-Hydroxy Fatty Acids in an Office Building during a Particle Intervention Study. Indoor Air 10, 2-12.

Hirvonen, M.-R.; Nevalainen, A.; Makkonen, N.; Mönkkönen, J.; SavolaiNEN, K. (1997) Induced Production of Nitric Oxide, Tumor Necrosis Factor, and Interleukin-6 in RAW 264.7 Macrophages by Streptomycetes from Indoor Air of Moldy Houses. Archives Environmental Health 52, 426-432.

Holt, J. G. (Ed.) (1984) Bergey's Manual of Systematic Bacteriology. Williams \& Wilkins, Baltimore, MD, USA

Huttunen, K.; Ruotsalainen, M.; Iivanainen, E.; Torkko, P.; Katila, M.-L.; Hirvonen, M.-R. (2000) Inflammatory Responses in RAW264.7 Macrophages Caused by Mycobacteria Isolated from Moldy Houses. Environmental Toxicology and Pharmacology 8, 237-244.

Huttunen, K.; Hyvärinen, A.; Nevalainen, A.; Komulainen, H.; HirvoNEN, M.-R. (2003) Production of Pro-inflammatory Mediators by Indoor Air Bacteria and Fungal Spores in Mouse and Human Cell Lines. Environmental Health Perspectives 111, 85-92.

Hyvärinen, A.; Vahteristo, M.; Meklin, T.; Jantunen, M.; Nevalainen, A.; Moschandreas, D. (2001) Temporal and Spatial Variation of Fungal Concentrations in Indoor Air. Aerosol Science and Technology 35, 688-695.

Jones, N.C.; Thornton, C.A.; Mark, D.; Harrison, R. M. (1999) Final Report DETR Project EPG 1/3/95, London.

Jones, N.; Thornton, C.; Mark, D.; Harrison, R. (2000) Indoor/Outdoor Relationships of Particulate Matter in Domestic Homes with Roadside, Urban and Rural Locations. Atmospheric Environment 34, 2603-2612.

Jones, T.P.; Williamson, B. J.; BéruBÉ, K.A.; Richards, R. J. (2001) Microscopy and Chemistry of Particles Collected on TEOM Filters: Swansea, South Wales, 1989-99. Atmospheric Environment 35, 3573-3583.

Jones, T.P.; Blackmore, P. R.; Leach, M.T.; BéruBÉ, K. A.; Sexton, K.; Richards, R. J. (2002) Characterisation of Airborne Particulates Collected Within and Proximal to an Open-Cast Coal-Mine: South Wales, UK. Environmental Monitoring and Assessment 75, 293-312.

Jussila, J.; Komulainen, H.; Huttunen, K.; Roponen, M.; Hälinen, A.; Hyvärinen, A.; Kosma, V.-M.; Pelkonen, J.; Hirvonen, M.-R. (2001) Inflammatory Responses in Mice after Intratracheal Instillation of Spores of Streptomyces californicus Isolated from Indoor Air of a Moldy Building. Toxicology and Applied Pharmacology 171, 61-69.

Jussila, J.; Komulainen, H.; Kosma, V.-M.; Nevalainen, A.; Pelkonen, J.; Hirvonen, M.-R. (2002) Spores of Aspergillus versicolor Isolated from Indoor Air of a Moisture-Damaged Building Provoke Acute Inflammation in Mouse Lungs. Inhalation Toxicology 14, 1261-1277.

Karlsson, A.S.; Hedren, M.; Almqvist, C.; Larsson, K.; Renstrom, A. (2002) Evaluation of Petri Dish Sampling for Assessment of Cat Allergen in Airborne Dust. Allergy 57, 164-168.

Katila, M.-L.; Mattila, J.; Brander, E. (1989) Enhancement of Growth of Mycobacterium Malmoense by Acidic $\mathrm{pH}$ and Pyruvate. European Journal of Clinical Microbiology and Infectious Diseases 8, 998-1000. 
LANDsberger, S.; Wu, D. (1995) The Impact of Heavy Metals from Environmental Tobacco Smoke on Indoor Air Quality as Determined by Compton Suppression Neutron Activation Analysis. Science of the Total Environment 173, 323-337.

Leaderer, B.P.; Belanger, K.; Triche, E.; Holford, T.; Gold, D. R.; Kim, Y.; Jankun, T.; Ren, P.; McSharry, J.E.; Platts-Mills, T.A.E.; Chapman, M.D; Bracken, M. B. (2002) Dust Mite, Cockroach, Cat and Dog Allergen Concentrations in Homes of Asthmatic Children in the Northeastern United States: Impact of Socioeconomic Factors and Population Density. Environmental Health Perspectives 110, 419-425.

Lemieux, P.; Ryan, J.; French, N.; HaAs, W.; Priebe, S.; Burns, D. (1998) Results of the September 1997 DOE/EPA Demonstration of Multimetal Continuous Emission Monitoring Technologies. Waste Management 18, 385-391.

Liang, Z.; Wei, G.T.; Irwin, R.; Walton, A.; Michel, R.; Sneddon, J. (1990) Determination of Sub-nanogram per Cubic Metre Concentrations in the Air of a Trace Metal Clean Room by Impaction Graphite Furnace Atomic Absorption and Laser Excited Atomic Fluorescence Spectrometry. Analytical Chemistry 62, 1452-1457.

Lin, X. J.; Reponen, T.A.; Willeke, K.; Grinshpun, S.A.; Foarde, K. K.; Ensor, D. S. (1999) Long-Term Sampling of Airborne Bacteria and Fungi into a Non-evaporating Liquid. Atmospheric Environment 33(26), 4291-4298.

Lioy, P. J.; Freeman, N. C. G.; Millette, J.R. (2002) Dust: A Metric for Use in Residential and Building Exposure Assessment and Source Characterization. Environmental Health Perspectives 110, 969-983.

Macher, J.M.; Ammann, H.; Burge, H.A.; Milton, D. K.; Morey, P.R. (Eds.) (1999) Bioaerosols: Assessment and Control. ACGIH, Cincinnati, OH, USA, 6-13.

Macher, J. M. (2001) Review of Methods to Collect Settled Dust and Isolate Culturable Microorganisms. Indoor Air - International Journal of Indoor Air Quality and Climate 11(2), 99-110.

Malm, W.C.; Gebhart, K.A.; Molenar, J.; Cahill, T.; Eldred, R.; Huffman, D. (1994) Examining the Relationship Between Atmospheric Aerosols and Light Extinction at Mount Rainier and North Cascades National Parks. Atmospheric Environment 28, 347-360.

Matousek, J. P.; Brodie, K. G. (1973) Direct Determination of Lead Airborne Particulates by Non-Flame Atomic Absorption. Analytical Chemistry 45(9), 1606-1609.

Miller, J.D.; Young, J.C. (1997) The Use of Ergosterol to Measure Exposure To Fungal Propagules in Indoor Air. American Industrial Hygiene Association Journal 58(1), 39-43.

Milton, D. K. (1999) Endotoxin and Other Bacterial Cell-Wall Components. In: Macher, J.M.; Ammann, H.A.; Burge, H.A.; Milton, D. K.; Morey, P.R. (Eds.) Bioaerosols - Assessment and Control, American Conference of Governmental Industrial Hygienists (ACGIH), Cincinnati, OH.

Moreno, T.; Jones, T. P.; Richards, R. J. (2003) Unpublished data. School of Biosciences, Cardiff University, Wales, UK.

Morris, K. J. (1995) Modern Microscopic Methods of Bioaerosol Analysis. In: Cox, C.S., Wathes, C. M. (Eds.) Bioaerosols Handbook. Lewis Publishers, Boca Raton, Florida, 285-316.

Morgan, A. J. (1984) X-ray Microanalysis in Electron Microscopy for Biologists. Royal Microscopy Society Microscopy Handbooks 05, Oxford University Press, Oxford. 
Morgan, A.J; Winters, C.; Sturzenbaum, S. (1999) X-ray Microanalysis Techniques. In: Hajibagheri, N. (Ed.) Methods in Molecular Medicine Biology, vol. 117, Electron Microscopy Methods and Protocols. Humana Press Inc., New Jersey, 45-276.

Murtoniemi, T.; Nevalainen, A.; SuUtari, M.; Toivola, M.; Komulainen, H.; Hirvonen, M.-R. (2001) Induction of Cytotoxicity and Production of Inflammatory Mediators in RAW264.7 Macrophages by Spores Grown on Six Different Plasterboards. Inhalation Toxicology 13, 233-247.

Nielsen, K.F.; Hansen, M.O.; Larsen, T. O.; Thrane, U. (1998) Production of Mycotoxins on Water-Damaged Gypsum Boards in Danish Buildings. International Biodeterioration \& Biodegradation, 42, 1-7.

Nielsen, K. F.; Gravesen, S.; Nielsen, P.A.; Andersen, B.; Thrane, U.; FRISVAD, J.C. (1999) Production of Mycotoxins on Artificially and Naturally Infested Building Materials. Mycopathologia, 145, 43-56.

Nielsen, K. F.; Huttunen, K.; Hyvrinen, A.; Andersen, B.; Jarvis, B.; Hirvonen, M.-R. (2001) Metabolite Profiles of Stachybotrys Isolates from Water-Damaged Buildings and their Induction of Inflammatory Mediators and Cytotoxicity in Macrophages. Mycopathologia 154, 201-205.

Nielsen, K. F.; Thrane, U. (2001) Fast Methods for Screening of Trichothecenes in Fungal Cultures Using Gas Chromatography-Tandem Mass Spectrometry. Journal of Chromatography A929(1/2), 75-87.

Olmez, I. (1989) Trace Element Signatures in Groundwater Pollution. In: Watson, J.G. (Ed.) Receptor Models in Air Resources Management: an International Speciality Conference, Air and Waste Management Association, San Francisco, 3-11.

Ondov, J. M.; Divita, F. (1993) Size Spectra for Trace Elements in Urban Aerosol Particles by Instrumental Neutron Activation Analysis. Journal of Radioanalytical and Nuclear Chemistry 167, 247-258.

Peltola, J.; Andersson, M.A.; Haahtela, T.; Mussalo-Rauhamaa, H.; Rainey, F.A.; Kroppenstedt, R. M.; Samson, R. A.; Salkinoja-Salonen, M. (2001) Toxic Metabolite Producing Bacteria and Fungus in an Indoor Environment. Applied and Environmental Microbiology 67(7), 3269-3274.

Pitt, J. I.; AbarCa, M. L.; Lopez, C. (2000) Mycotoxins and Toxigenic Fungi. Medical Mycology 38 (Suppl. 1), 41-46.

Reponen, T.; Willeke, K.; Grinshpun, S.; Nevalainen, A. (2001) Biological Particle Sampling. In: Baron, P. A.; Willeke, K. (Eds.) Aerosol Measurement, 2nd ed. John Wiley \& Sons, New York, 751-777.

Rintala, H.; Nevalainen, A.; SuUtari, M. (2002) Diversity of Streptomycetes in Water-Damaged Building Materials Based on 16S rDNA Sequences. Letters in Applied Microbiology 34, 439-443.

Roponen, M.; Toivola, M.; Meklin, T.; Ruotsalainen, M.; Komulainen, H.; Nevalainen, A.; Hirvonen, M.-R. (2001) Differences in Inflammatory Responses and Cytotoxicity in RAW264.7 Macrophages Induced by Streptomyces anulatus Grown on Different Building Materials. Indoor Air 11, 179184.

Roponen, M.; Toivola, M.; Alm, S.; Nevalainen, A.; Jussila, J.; Hirvonen, M.-R. (2003) Inflammatory and Cytotoxic Potential of the Airborne Particle Material Assessed by Nasal Lavage and Cell Exposure Methods. Inhalation Toxicology 15(1), 23-28.

Rose, C. S. (1999) Antigens. In: Macher, J. M.; Ammann, H. A.; Burge, H. A.; Milton, D. K.; Morey, P. R. (Eds.) Bioaerosols - Assessment and Control. American Conference of Governmental Industrial Hygienists (ACGIH), Cincinnati, OH, 1-11. 
Rotman, B.; Cote, M.A. (2003) Application of Real-Time Biosensor to Detect Bacteria in Platelet Concentrates. Biochemical and Biophysical Research Communications 300, 197-200.

Rylander, R.; Norrhall, M.; Engdahl, U.; Tunsäter, A.; Holt, P. G. (1998) Airways Inflammation, Atopy, and $(1 \rightarrow 3)-\beta$-D-Glucan Exposures in Two Schools. American Journal of Respiratory and Critical Care Medicine 158, 1685-1687.

Samson, R.A.; Flannigan, B.; Flannigan, M.E.; Verhoeff, A. P.; Adan, O.C.G.; Hoekstra, E. S. (1994) Health Implications of Fungi in Indoor Environments. Elsevier, Amsterdam, 531-538.

Sandor, E.; Szentirmai, A.; Paul, G.C.; Thomas, C. R.; Pocsi, I.; Karaffa, L. (2001) Analysis of the Relationship Between Growth, Cephalosporin C Production, and Fragmentation in Acremonium chrysogenum. Canadian Journal of Microbiology 47(9), 801-806.

Saraf, A.; Larsson, L. (1996) Use of Gas Chromatography/Ion-Trap Tandem Mass Spectrometry for the Determination of Chemical Markers of Microorganisms in Organic Dust. Journal of Mass Spectrometry 31, 389-396.

Saraf, A.; Larsson, L.; Burge, H.; Milton, D. K. (1997) Quantification of Ergosterol and 3-Hydroxy Fatty Acids in Settled House Dust by Chromatography-Mass Spectrometry: Comparison with Fungal Culture and Determination of Endotoxin by a Limulus Amebocyte Lysate Assay. Applied and Environmental Microbiology 63(7), 2554-2559.

Saraf, A.; Larsson, L.; Larsson, B. M.; Larsson, K.; Palmberg, L. (1999) House Dust Induces IL-6 and IL-8 Response in A549 Epithelial Cells. Indoor Air 9(4), 219-225.

Smoragiewicz, W.; Cossette, B.; Boutard, A.; Krzystyniak, K. (1993) Trichothecene Mycotoxins in the Dust of Ventilation Systems in Office Buildings. International Archives of Occupational and Environmental Health 65(2), 113-117.

Sorenson, W.; Frazer, D.; Jarvis, B.B.; Simpson, J.; Robinson, V. (1987) Trichothecene Mycotoxins in Aerosolized Conidia of Stachybotrys atra. Applied and Environmental Microbiology 53, 1370-1375.

SzPonar, B.; LaRsson, L. (2001) Use of Mass Spectrometry for Characterizing Microbial Communities in Bioaerosols. Annals of Agricultural and Environmental Medicine 8(2), 111-117.

Thomas, S.B.; Bofinger, N. D.; Morawska, L.; Selby, M. J. (1997) Investigations of the Source of Blank Problems in the Measurement of Lead in Submicron Airborne Particulates by ICP-MS. Journal of Analytical Atomic Spectroscopy 12, 553-556.

Thomas, S. B.; Morawska, L. (2002) Size-Selected Particles in an Urban Atmosphere of Brisbane, Australia. Atmospheric Environment 36, 4277-4288.

Thrane, U.; Poulsen, S. B.; Nirenberg, H. I.; Lieckfelt, E. (2001) Identification of Trichoderma Strains by Image Analysis of HPLC Chromatograms. FEMS Microbiol. Letters 203, 249-255.

Toivola, M.; Alm, S.; Reponen, T.; Kolari, S.; Nevalainen, A. (2002) Personal Exposures and Microenvironmental Concentrations of Particles and Bioaerosols. Journal of Environmental Monitoring 4, 166-174.

Tuomi, T.; Reijula, K.; Johnsson, T.; Hemminki, K.; Hintikka, E.-L.; LinDroos, O.; Kalso, S.; Koukila-Käнкölä, P.; Mussalo-RauhamaA, H.; НAaHTELA, T. (2000) Mycotoxins in Crude Building Materials from Water-Damaged Buildings. Applied and Environmental Microbiology 66, 1899-1904. 
Tuomi, T.; Johnsson, T.; HintikKA, E. L.; Reijula, K. (2001) Detection of Aflatoxins (G1-2, B1-2), Sterigmatocystin, Citrinine and Ochratoxin A in Samples Contaminated by Microbes. Analyst 126(9), 1545-1550.

Warley, A. (1997) X-ray Microanalysis for Biologists. Practical Methods in Electron Microscopy, Vol. 16. Glauert, A. M. (Ed.) Portland Press, London.

Willeke, K.; Macher, J.M. (1999) Air Sampling. In: Macher, J.M.; Ammann, H.A.; Burge, H.A; Milton, D. K.; Morey, P.R. (Eds.) Bioaerosols, Assessment and Control. American Conference of Governmental Industrial Hygienists, Cincinnati, 1-25.

Wittwer, C.T.; Herrmann, M. G.; Moss, A. A.; Rasmussen, R. P. (1997) Continuous Fluorescence Monitoring of Rapid Cycle DNA Amplification. Biotechniques 22, 130-131.

Woodriff, R.; Lech, J.F. (1972) Determination of Trace Lead in the Atmosphere by Furnace Atomic Absorption. Analytical Chemistry 44(7), 13231325.

Yacoub-George, E.; Meixner, L.; Scheithauer, W.; Koppi, A.; Drost, S.; Wolf, H.; Danapel, C.; Feller, K.A. (2002) Chemiluminescence Multichannel Immunosensor for Biodetection. Analytica Chimica Acta 457, 3-12.

YANG, K.; WANG, J.-F.; LI, X.-J.; FenG, X.; DuAn, S.-D. (2001) Strain Selection of Metarrhizium anisopliae by Image Analysis of Colony Morphology for Consistency of Steroid Biotransformation. Biotechnology and Bioengineering 75(1), 53-62.

Zoller, W.H.; Gordon, G.E. (1970) Instrumental Neutron Activation Analysis of Atmospheric Pollutants Utilizing Ge(Li) $\gamma$-ray Detectors. Analytical Chemistry $42,257-265$. 